\title{
Global transport and localized layering of metallic ions in the upper atmosphere
}

\author{
L. N. Carter ${ }^{1}$, J. M. Forbes ${ }^{2}$ \\ ${ }^{1}$ Center for Space Physics, Boston University, Boston, MA 02215 \\ ${ }^{2}$ Department of Aerospace Engineering Sciences, Campus Box 429, University of Colorado, Boulder, CO $80303-0429$ USA
}

Received: 6 November 1997 / Revised: 17 July 1998 / Accepted: 24 August 1998

\begin{abstract}
A numerical model has been developed which is capable of simulating all phases of the life cycle of metallic ions, and results are described and interpreted herein for the typical case of $\mathrm{Fe}^{+}$ions. This cycle begins with the initial deposition of metallics through meteor ablation and sputtering, followed by conversion of neutral $\mathrm{Fe}$ atoms to ions through photoionization and charge exchange with ambient ions. Global transport arising from daytime electric fields and poleward/ downward diffusion along geomagnetic field lines, localized transport and layer formation through descending convergent nulls in the thermospheric wind field, and finally annihilation by chemical neutralization and compound formation are treated. The model thus sheds new light on the interdependencies of the physical and chemical processes affecting atmospheric metallics. Model output analysis confirms the dominant role of both global and local transport to the ion's life cycle, showing that upward forcing from the equatorial electric field is critical to global movement, and that diurnal and semidiurnal tidal winds are responsible for the formation of dense ion layers in the 90-250 km height region. It is demonstrated that the assumed combination of sources, chemical sinks, and transport mechanisms actually produces F-region densities and E-region layer densities similar to those observed. The model also shows that zonal and meridional winds and electric fields each play distinct roles in local transport, whereas the ion distribution is relatively insensitive to reasonable variations in meteoric deposition and chemical reaction rates.
\end{abstract}

Key words. Ionosphere (ion chemistry and composition; ionosphere-atmosphere interactions).

Correspondence to: J. M. Forbes

\section{Introduction}

\subsection{Brief history of observational work}

Metallic ions have been the focus of upper atmosphere scientific investigations for some time. The first in-situ measurements were made by rocket-borne mass spectrometer (Istomin, 1963), revealing peak densities of $\mathrm{Fe}^{+}\left(1.5 \times 10^{4} \mathrm{~cm}^{-3}\right), \mathrm{Mg}^{+}\left(1.4 \times 10^{4} \mathrm{~cm}^{-3}\right)$ and $\mathrm{Ca}^{+}$ $\left(0.5 \times 10^{3} \mathrm{~cm}^{-3}\right)$ near $105 \mathrm{~km}$. Similar rocket measurements were reported by Narcisi and Bailey (1965) and Narcisi (1967), including a flight during the Leonid meteor shower which conclusively demonstrated that meteor ablation is the mechanism responsible for production of metallic ions in the upper atmosphere. Numerous other rocket flights have subsequently provided data on metallic ion distributions (i.e., Young et al., 1967; Aiken and Goldberg, 1973; Aiken et al., 1974, 1977; Goldberg and Witt, 1977; Zbinden et al., 1975; Alpers et al., 1993). Some of these provided evidence for connections between metallic ion layers and sporadic-E $\left(\mathrm{E}_{\mathrm{s}}\right)$, and others attempted to establish connections between metallic ion cluster molecules and the formation of noctilucent clouds. Most recently, Kopp (1997) summarizes results from five rocket flights in the lower ionosphere, noting that the dominant metal ion on all flights is $\mathrm{Fe}^{+}$, with column density about a factor of two larger than $\mathrm{Mg}^{+}$, on average. An order of magnitude increase in total metal ion abundance during the Perseid meteor shower of August 12, 1976, is also reported by Kopp (1977).

Lidar represents the new tool for observing $\mathrm{Fe}$ in the 80-110 km region (Gardner et al., 1993; Kane and Gardner, 1993; Kane et al., 1991, 1993, and references contained therein). The high spatial and temporal resolutions afforded by lidars have revealed the "sudden" or "sporadic" appearance of thin $(\sim 1 \mathrm{~km})$ layers of $\mathrm{Na}$ and $\mathrm{Fe}$, which form within a time scale of minutes. On the basis of simultaneous observations of 
sporadic $\mathrm{E}, \mathrm{Fe}, \mathrm{Na}$ and $\mathrm{Ca}^{+}$, the authors mentioned suggest a connection between sporadic $\mathrm{E}$, neutralization of $\mathrm{Fe}^{+}$, and the formation of sporadic Fe layers. It is not our intent in the present work, however, to attempt to simulate metallic chemistry over these short spatial and temporal scales.

The first report of satellite-based in-situ measurement of $\mathrm{Fe}^{+}$is that of Hanson and Sanitani (1970), based on the retarding potential analyzer experiment on OGO-6. The satellite altitude was between 500 and $600 \mathrm{~km}$, well above the meteor ablation region (about $90-110 \mathrm{~km}$ ). Densities of order $200 \mathrm{~cm}^{-3}$ were found. A tentative conclusion was that the $E \times B$ drift driven by the equatorial dynamo electric field was the active agent lifting ions to the observed heights, at which point the "fountain effect" takes over and transports the ions, via gravity and diffusion, to higher latitudes along the geomagnetic field lines. Subsequent papers reinforced the fountain effect interpretation (Hanson et al., 1972) and revealed a strong correlation between equatorial spread-F (ESF) and the presence of $\mathrm{Fe}^{+}$. Other analyses of data from OGO-4 and OGO-6 (Taylor, 1973), ESRO TD-1A (Gerard, 1976; Gerard and Monfils, 1978), and AE-C and AE-E (Grebowsky and Brinton, 1978; Grebowsky and Reese, 1989) revealed similar ion densities, consistent with the idea of upward vertical transport near the magnetic equator. Recent observations by the GLO instrument on the Space Shuttle have provided the first simultaneous observations of $\mathrm{Mg}$ and $\mathrm{Mg}^{+}$in the thermosphere (Gardner et al., 1995). The salient features of the $\mathrm{Mg}^{+}$distributions near the magnetic equator appear to be driven by vertical $E \times B$ drifts (McNeil et al., 1996).

\subsection{Laboratory measurements of reaction rates, and previous theory and modelling efforts}

The sophistication of theories and models have increased in concert with the availability of experimental data. The formation of thin, long-lived dense layers in the E-region were first connected with neutral wind shears in Earth's ambient magnetic field by Dungey (1956, 1959). Dungey's $(1956,1959)$ ideas were further developed and applied to sporadic-E layer formation by MacLeod (1966), Whitehead $(1961,1966)$ and Chimonas and Axford (1968), among others. The importance of diffusion to the dynamics of metallics was noted by Gadsden (1970). In addition, the roles of various chemical reactions in determining the life cycles of neutral and ionized metallics began to be realized (i.e., Swider, 1969; Richter and Sechrist, 1979a, b). An early summary of the relevant rate coefficients, both measured and estimated, is provided in Brown (1973). In response to the needs of more comprehensive models, recent efforts to measure chemical reaction rates in the laboratory have been led by J. Plane and colleagues (Plane, 1991; Plane and Helmer, 1994, 1995; Plane and Husain, 1986).

The first attempts to simulate sporadic E-layer dynamics were those of Chimonas and Axford (1968) and MacLeod et al. (1975). These results supported the hypothesis that $\mathrm{E}_{\mathrm{s}}$ is caused by the accumulation of metallic ions in convergent nulls in the vertical ion drift associated with neutral wind profiles. Mathews and Bekeny (1979) approached the problem by computing ion trajectories consistent with descending tidal wind structures in the E-region, and demonstrating the existence of descending and stagnation phases of ion motion. These studies did not consider the effects of diffusion, gravity, electric fields, metallic and ambient ion chemistry, or any serious consideration of the metallic ion source. Similarly, Wilkinson et al. (1972) compared observed ion layers with convergent nulls in a simulated diurnal wind field over Townsville, Australia $\left(20^{\circ} \mathrm{S}, 147^{\circ} \mathrm{E}\right)$. The wind field was generated by the NCAR TIGCM (thermosphere/ionosphere general circulation model; Roble et al., 1988) with the Richmond empirical model (Richmond et al., 1980) used for electric field input. Both converging and diverging windshear nulls were found, with the typical pattern of descent followed by stagnation.

Nygren et al. (1984), Bristow and Watkins (1991) and Kirkwood and Von Zahn (1991) focused on the formation of layers at high latitudes $\left(I=75^{\circ}\right)$ where electric fields are considered the predominant driving force, in contrast to the more important role of neutral winds at mid-latitudes. These works, which neglected neutral winds, showed that thin ion layers formed in the 90 $130 \mathrm{~km}$ region provided the E-field was suitably oriented. Osterman et al. (1994) considered the formation of layers by ambient ions (mostly $\mathrm{NO}^{+}$) in the nighttime ionosphere over Arecibo taking into account the pertinent ionospheric chemical reactions and a simple meridional wind model which gave rise to a descending convergent null, but without consideration of electric fields. Their results illustrate the gradual growth and intensification of descending layers of ambient ions, but peak densities are limited to 3000 to $5000 \mathrm{~cm}^{-3}$ due to the relatively shorter lifetimes of ambient molecular ions.

The work of Fesen (1981) and Fesen et al. (1983) focused on the global distribution of $\mathrm{Mg}^{+}$due to transport in the meridional plane by neutral winds, electric fields, and diffusion and gravity in the presence of a realistic magnetic field. Photoionization and ionatom interchange reactions between $\mathrm{Mg}^{+}$and ambient species were included. Seasonal-latitudinal and local time distributions of $\mathrm{Mg}^{+}$ions, including equatorial asymmetries due to neutral winds, were shown to be in reasonable accord with in-situ satellite measurements mentioned previously. McNeil et al. (1996) recently solved the continuity equations for $\mathrm{Mg}$ and $\mathrm{Mg}^{+}$in the geomagnetic equatorial plane, and made comparisons with GLO1 Space Shuttle measurements (Gardner et al., $1994 ; 1995)$ of $2795 \AA$ and $2802 \AA$ emissions. Although the model only included transport by diffusion and vertical drifts (neglecting neutral winds and meridional transport), the absolute magnitudes and dawn-dusk asymmetries in predicted radiances were quite similar to those observed. 


\subsection{Scope and contributions of the present work}

Despite the aforementioned progress in theory and modelling, some gaps and shortcomings remain. Previous efforts have each focused on a subset of physical processes, and by imposing reasonable approximations or constraints, new insights into various facets of upper atmosphere metallics have been developed. However, to date there is not a single study which has demonstrated, via numerical simulation, that the currently-accepted wind distributions, electric fields, diffusion rates, meteoric deposition rates and chemical reaction sets are capable of working together to actually produce the amplitude of total plasma density or metallic ion density layers that have been observed by rocket-borne instruments or radio diagnostics. In addition, no work has attempted to tie together the global transport and distribution of metallic ions with localized layering processes to demonstrate that realistic meteoric deposition rates, F-region metallic ion densities, layer densities and chemical loss rates can all be achieved selfconsistently. Progress in the latter direction has, of course, been impeded by the numerical difficulties involved in addressing a wide range of spatial and temporal scales associated with chemistry and transport in a single model. The present work is a numerical modeling effort which successfully deals with all of these issues.

The physical processes considered in the present modeling effort are depicted schematically in Fig. 1. The latitudinal boundaries of the model are $0^{\circ}$ and $45^{\circ}$ (differences between geomagnetic and geographic coordinates are not considered), and the height boundaries are $90 \mathrm{~km}$ and $4000 \mathrm{~km}$. We focus our attention here on $\mathrm{Fe}$ and $\mathrm{Fe}^{+}$since these are the most abundant of the upper atmosphere metallic atoms and ions, but the results are easily extrapolated to $\mathrm{Mg} / \mathrm{Mg}^{+}, \mathrm{Ca} / \mathrm{Ca}^{+}$, etc. In the model, $\mathrm{Fe}$ and $\mathrm{Fe}^{+}$are assumed to be deposited by meteor ablation in the 100-130 km height range (an extensive discussion including many historical references

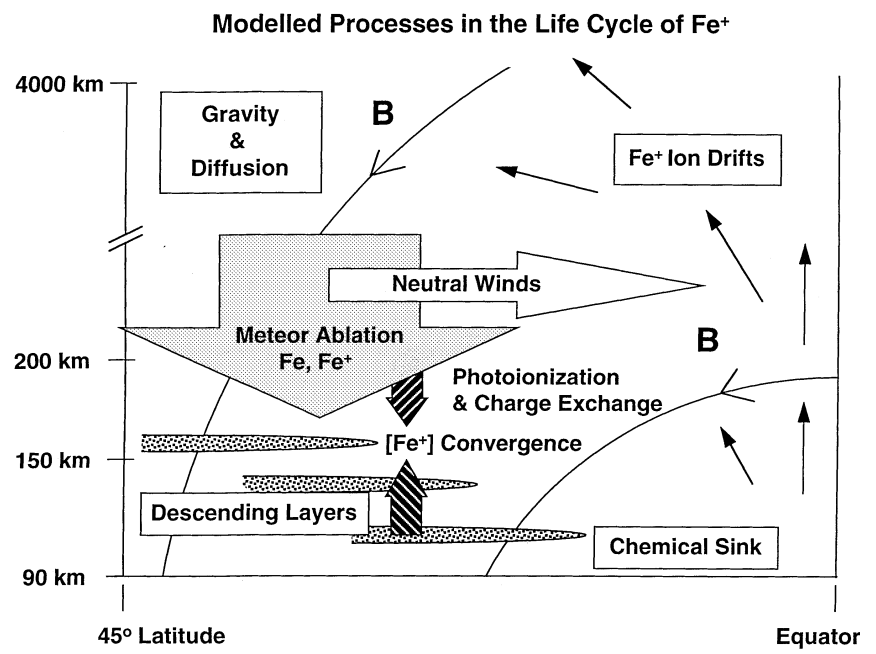

Fig. 1. Schematic of physical processes which are included in the model may be found in Carter, 1995). Various processes such as photoionization, recombination, charge transfer reactions, etc. are assumed to be operative in this height regime. Electric fields redistribute $\mathrm{Fe}^{+}$in the meridional plane and with respect to local time; this process is most pronounced at low latitudes in connection with the "fountain effect". Gravity and diffusion serve to redistribute $\mathrm{Fe}^{+}$along field lines. Neutral winds also transport $\mathrm{Fe}$ and $\mathrm{Fe}^{+}$in the meridional plane, and if vertical shears are sufficiently extreme below about $180 \mathrm{~km}$, metallic ion layers form which descend downward following the phase progression of upward-propagating tidal motions. When ions descend below about $100 \mathrm{~km}$, a variety of three-body reactions initiate a chemical chain which constitutes the ultimate sink for the $\mathrm{Fe}^{+}$ions. The numerical simulations are performed using a finite element technique that easily accomodates a variable spatial grid and separate time steps for each of the chemical and transport processes.

The following section details the numerical model, the $\mathrm{Fe}^{+}$chemistry, the dynamical and electrodynamic inputs to the model, and other input parameters. Section 3 describes the results of several numerical simulations, illustrating localized layering, the effects of large-scale transport by winds and electric fields, and the responses to geomagnetic storm and meteor shower perturbations. Results and conclusions are summarized in Sect. 4.

The present work represents an abbreviated selection of results from the work of Carter (1995), which is available from J. Forbes upon request. Additional details concerning model inputs, model outputs, numerical algorithms, etc. may also be found there.

\section{The model}

\subsection{Numerical framework}

The numerical model employed for the present study is based upon the method of finite elements, or finite element simulation (FES). In the current context, the FES technique is a computational method for solving the coupled continuity equations for $\mathrm{Fe}$ and $\mathrm{Fe}^{+}$subject to various transport processes:

$\frac{\partial N_{M}}{\partial t}=S \pm k_{n}\left[N_{i}\right]\left[N_{j}\right]+\vec{\nabla} \cdot N_{M} \vec{v}$

where

$N_{M}=$ concentration of $\mathrm{Fe}$ or $\mathrm{Fe}^{+}$

$t=$ time

$S=$ source function (presently, meteor ablation)

$k_{n}=$ rate coefficient of $n$th reaction between ith and jth species, leading either to production $(+)$ or loss (-) of $N_{M}$

$\vec{v}=$ transport velocity of $N_{M}$ (see Sect. 2.3)

The FES technique consists of dividing the system of interest into volumetric "cells". The infinitesimal quantities in the continuity equation are then replaced by finite quantities derived from the particular cell geometry chosen (i.e., cylindrical, rectangular). The changes 
in concentration within a particular cell are calculated independently for each individual photochemical and transport process. Each chemical reaction and transport process proceeds with its own individual time step (determined by the time constant of the process), with all processes synchronized by a "master clock". "Transport" here is realized by movement into or out of a particular cell in concert with adjacent cells, while chemical production and loss are taking place within each individual cell. Each cell must be sufficiently small that both chemical and transport processes can be treated as uniform throughout the cell's interior. Time steps to maintain stability and convergence must be chosen so that the concentration of any given species does not change too much (i.e., $<5 \%$ ) within a cell during any given time step. The time step is automatically adjusted within the program to conform to a given depletion limit specified by the user, usually after some trial and error.

The model was run in two configurations. The first was a one-dimensional version consisting of a stack of 1$\mathrm{km}$ cells extending from 90 to $220 \mathrm{~km}$ at the latitude of Arecibo $\left(18^{\circ} \mathrm{N}, 67^{\circ} \mathrm{W}\right.$ geographic; $30^{\circ} \mathrm{N}, 2^{\circ} \mathrm{E}$ geomagnetic). For these runs convergence was achieved within five days of simulation, with time steps for the various processes ranging from $0.01 \mathrm{~s}$ to $10.24 \mathrm{~s}$. Cell configurations for the two-dimensional (meridional plane) version of the model are depicted in Fig. 2. The cell geometry consists of a series of radial cell stacks extending from the equator (magnetic and geographic equators were assumed coincident) to $45^{\circ} \mathrm{N}$, each cell spanning $2.25^{\circ}$ meridionally, for a total of 21 stacks. The vertical configuration was divided into low/middle/high altitude regimes: 56 cells of $1 \mathrm{~km}$ height from 100 to $155 \mathrm{~km} ; 30$ cells of $10 \mathrm{~km}$ height from 160 to $450 \mathrm{~km}$; and 36 cells, each $100 \mathrm{~km}$ in height, extending from $500 \mathrm{~km}$ up to $4000 \mathrm{~km}$. Within this scheme global meridional transport is dominant in the high regime, and metallic layer formation in the lowest region, with the middle region acting as a transitional zone. Experimentation with the 1-D model showed that placing the lower boundary at $100 \mathrm{~km}$ had no effect on results at higher altitudes. Since our main interest is in $\mathrm{Fe}^{+}$, once

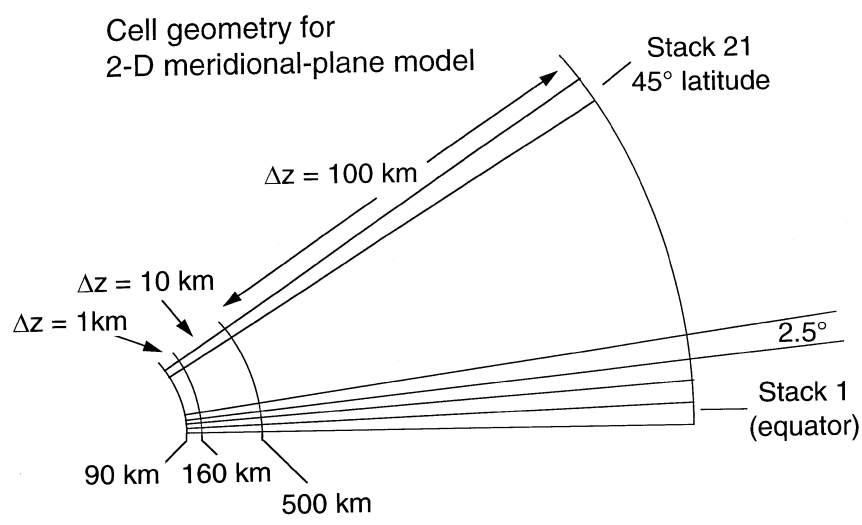

Fig. 2. Finite-element cell geometry and height resolutions used in the model it is lost chemically near the lower boundary its fate is no longer of concern. Since the 3-body chemical reactions below $100 \mathrm{~km}$ are fast, requiring small time steps, placing the boundary at $100 \mathrm{~km}$ enabled us to economize computational effort for the more demanding 2-D simulations. Further, it might be suspected that, on the basis of L-shell geometry, a transport model that spans the $0^{\circ}$ to $45^{\circ}$ sector should extend to $2 \mathrm{R}_{\mathrm{E}}$, or $6400 \mathrm{~km}$, but this was found unnecessary; the upward flow of plasma in the equatorial region due to $\mathrm{E} \times \mathrm{B}$ drift turns poleward along field lines well before that height, and $4000 \mathrm{~km}$ was deemed sufficiently high for an upper limit altitude.

The present FES code is based on previous versions which were used to simulate the midnight collapse of the ionosphere over Arecibo (Crary and Forbes, 1986) and the dispersion of chemicals in the ionosphere (Mendillo et al., 1993). In addition to Carter (1995), the reader is referred to this latter reference for details of the timestepping algorithm, the handling of diffusive transport processes, and other details of the FES technique.

\subsection{Source function}

Although meteor ablation is widely accepted as the source of upper-atmosphere neutral and ionized metallics, there still exist wide variations in estimates for most of the key parameters: (1) total mass influx; (2) fraction of meteoric mass of metallic composition; (3) fractions of metallic mass in neutral and in ionized form; (4) the vertical profile of deposition; and (5) diurnal, seasonal and geographic variations of meteoric flux. From the modeling perspective, the vertical profile is probably the most critical of the five; (1), (2) and (3) affect only the absolute magnitudes of $\mathrm{Fe}$ and $\mathrm{Fe}^{+}$, amounting to merely a scaling issue, and (5) is considered the most settled, with a relatively small range of published estimates.

Based on a review of observational data (Carter, 1995), the total meteor flux is assumed to be 200 tons per day of meteoric material. Results of a thorough analysis by Mason (see Plane, 1991 and references cited therein) were adopted for the mass fraction, giving $11.5 \%$ of the total mass influx for $\mathrm{Fe}$. A rough estimate of $5 \%$ has been assigned for both the ionized and nonionized (atomic vapor) fractions in the source function (Carter, 1995). Carter (1995) presents some computer simulations where this latter quantity was varied.

Published opinions concerning the vertical profile of meteoric deposition differ sufficiently that three different profiles were investigated in the present study, with peak altitudes near $130 \mathrm{~km}, 110 \mathrm{~km}$, and $90 \mathrm{~km}$. In each case the profiles possess a width at half-maximum of about $30-40 \mathrm{~km}$. The lowest-altitude profile is based upon optical meteor train data (see Carter, 1995, for a review). The medium-altitude profile is consistent with a conservative interpretation of $\mathrm{VHF} / \mathrm{HF} / \mathrm{MF}$ meteor radar results, while the high-altitude profile is based upon an implied-but-unseen profile based on radar data extrapolation (Carter, 1995). Published data on the diurnal 
variation at middle latitudes and March equinox are consistent with a diurnal variation with maximum near 0300-0900 LT and minimum at about one-third the amplitude around 1500-2100 LT. The latitudinal variation is based on a study by Elford and Hawkins (1964), and is well represented by a modified cosine function of the form $1.43 \cdot\left(0.6 \cdot \cos ^{2}(\right.$ lat $\left.)+0.4\right)$.

\section{$2.3 \mathrm{Fe} / \mathrm{Fe}^{+}$Chemistry}

The chemical reactions and respective rate constants used in the 2-D version of the model are, with exceptions noted later, estimates reported in Brown (1973) for a nominal temperature of $200 \mathrm{~K}$, and are shown in Table 1. Estimates are mainly based on similar analagous reactions whose rate constants are known. Measured rates include $\mathrm{k}_{7}, \mathrm{k}_{13}, \mathrm{k}_{14}, \mathrm{k}_{15}$ (Rutherford and Vroom, 1972) and $\mathrm{k}_{10}$ (Ferguson and Fehsenfeld, 1968). The radiative recombination rate $\left(\mathrm{k}_{2}\right)$ is a theoretical estimate (Bates and Dalgarno, 1962). In addition to photoionization of $\mathrm{Fe}$ and radiative recombination of $\mathrm{Fe}^{+}$, the reaction set covers charge exchange, dissociative recombination, oxidation/reduction of $\mathrm{Fe} / \mathrm{Fe}^{+}$, and molecular formation via three-body reactions. Nine additional reactions were included in the 1-D simulations, but were excluded in the 2-D simulations since their effects were negligible. Absorption of solar radiation by $\mathrm{O}_{2}$ at and below the $\mathrm{Fe}$ ionization wavelength of $1569 \AA$ was taken into account in calculating the production of $\mathrm{Fe}^{+}$from photoionization of $\mathrm{Fe}$.

Another aspect of chemistry in the model is the implicit inclusion of an undefined "perfect" chemical sink below the bottom boundary $(85 \mathrm{~km}$ for the 1-D simulations; $100 \mathrm{~km}$ for the 2-D grid). Specifically, it is

Table 1. Chemical reactions and rate constants $\left(\mathrm{cm}^{3} \mathrm{~s}^{-1} ; \mathrm{cm}^{6} \mathrm{~s}^{-1}\right.$ for three-body reactions) used in the 2-D version of the model, based on the compilation by Brown (1973). Temperature dependences for all rate constants listed here, except for the last three, are unknown or highly uncertain and hence are kept constant in the simulations corresponding to a nominal value of $T=200 \mathrm{~K}$. Rate constants for the last three reactions are assumed to vary between $T=150 \mathrm{~K}$ and $T=1350 \mathrm{~K}$, based on the measurements of Rutherford and Vroom (1972), also included in Brown (1973); the rates listed here for these reactions are applicable to the range $750 \mathrm{~K}-1050 \mathrm{~K}$

\begin{tabular}{ll}
\hline $\mathrm{Fe}+h v \rightarrow \mathrm{Fe}^{+}+\mathrm{e}^{-}$ & $J_{1}=5.0 \times 10^{-7} \mathrm{~S}^{-1}$ \\
$\mathrm{Fe}+\mathrm{e}^{-} \rightarrow \mathrm{Fe}^{+}+7.90 \mathrm{ev}$ & $k_{2}=1.0 \times 10^{-12}$ \\
$\mathrm{FeO}^{+}+\mathrm{e}^{-} \rightarrow \mathrm{Fe}+\mathrm{O}$ & $k_{3}=4.5 \times 10^{-7}$ \\
$\mathrm{FeO}_{2}^{+}+\mathrm{O} \rightarrow \mathrm{FeO}^{+}+\mathrm{O}_{2}$ & $k_{4}=1.0 \times 10^{-10}$ \\
$\mathrm{FeO}^{+}+\mathrm{O} \rightarrow \mathrm{Fe}^{+}+\mathrm{O}_{2}$ & $k_{5}=1.0 \times 10^{-10}$ \\
$\mathrm{FeN}_{2}^{+}+\mathrm{O} \rightarrow \mathrm{FeO}^{+}+\mathrm{N}_{2}$ & $k_{6}=1.0 \times 10^{-10}$ \\
$\mathrm{Fe}^{+} \mathrm{O}_{2}^{+} \rightarrow \mathrm{FeO}+\mathrm{O}^{+}+\mathrm{O}^{-11}$ & $k_{8}=2.0 \times 10^{-6}$ \\
$\mathrm{FeO}_{2}^{+}+\mathrm{e}^{-} \rightarrow \mathrm{Fe}+\mathrm{O}_{2}$ & $k_{9}=2.0 \times 10^{-6}$ \\
$\mathrm{FeN}_{2}^{+}+\mathrm{e}^{-} \rightarrow \mathrm{Fe}+\mathrm{N}_{2}$ & $k_{10}=2.5 \times 10^{-30}$ \\
$\mathrm{Fe}^{+}+\mathrm{O}_{2}+M \rightarrow \mathrm{FeO}_{2}^{+}+M$ & $k_{11}=2.5 \times 10^{-30}$ \\
$\mathrm{Fe}^{+}+\mathrm{N}_{2}+M \rightarrow \mathrm{FeN}_{2}^{+}+M$ & $k_{12}=2.5 \times 10^{-30}$ \\
$\mathrm{Fe}^{+}+\mathrm{O}^{+} \rightarrow \rightarrow \mathrm{FeO}^{+}+M$ & $k_{13}=7.0 \times 10^{-10}$ \\
$\mathrm{Fe}+\mathrm{NO}^{+} \rightarrow \mathrm{Fe}^{+}+\mathrm{NO}^{+}$ & $k_{14}=9.4 \times 10^{-10}$ \\
$\mathrm{Fe}+\mathrm{O}_{2}^{+} \rightarrow \mathrm{Fe}^{+}+\mathrm{O}_{2}$ & $k_{15}=2.0 \times 10^{-9}$ \\
$\mathrm{Fe}+\mathrm{O}^{+} \rightarrow \mathrm{Fe}^{+}+\mathrm{O}$ &
\end{tabular}

assumed that one or more ion capture mechanisms below this altitude ensures that any $\mathrm{Fe}^{+}$traversing the bottom cell lower boundary is either converted to a compound or a cluster ion and continues a downward migration into the stratosphere, as this is commonly believed to be the metallic ion "endpath" (Richter and Sechrist, 1979b). Thus the bottom boundary condition is that all $\mathrm{Fe}^{+}$ions transiting this boundary are permanently lost to an implicit chemical sink; the top boundary condition similarly treats upward-moving ions as being lost via diffusion into the upper ionosphere/exosphere.

\subsection{Other model inputs}

It is not computationally possible, or necessary, to selfconsistently compute all of the parameters necessary to determine the global and localized distributions of $\mathrm{Fe}^{+}$ ions in the upper atmosphere (i.e., neutral winds, electric fields, major species neutral and in composition, etc.). Moreover, our intent here is not to reproduce any particular experimental data set, but to demonstrate the types of global and local metallic ion distributions that are consistent with wind, electric field and major species concentrations that are broadly representative of the average state of the atmosphere. Therefore, a number of parameters in the model are specified externally, as described later. This approach is justified for purposes of the present study, given the apparent ubiquity of metallic ion layers and F-region metallic ion populations revealed in a considerable body of experimental data.

The zonal and meridional components of the model wind field at $18^{\circ} \mathrm{N}$ are illustrated in Fig. 3. This model is based upon the formulation of Crary and Forbes (1986), whose modelling effort captures many of the observed nighttime dynamical changes in the ionosphere over Arecibo. The model components consist of the mean, diurnal and semidiurnal tidal winds described in Forbes $(1982 \mathrm{a}, \mathrm{b})$, with some adjustments so as to reproduce average observed winds over Arecibo for non-winter conditions (Harper, 1981). An alternative wind model (Morton et al., 1993; Tong et al., 1988), applicable to January conditions over Arecibo and which contains a 6-h tidal component, was evaluated against the Forbes/ Harper model. Since both exhibited similar descending and stagnation phases for the convergent nulls responsible for layer formation, only results for the Forbes/ Harper model are presented here. Some results from the Morton/Tong model may be found in Carter (1995). For both wind models, a latitudinal dependence of $\cos (4$ (lat $\left.-22.5^{\circ}\right)$ ) was applied to force wind-induced transport to zero at the meridional boundaries of zero and 45 north, in view of horizontal-flow boundary conditions.

Eddy diffusion in the model was set at $10^{6} \mathrm{~cm}^{2} \mathrm{~s}^{-1}$ below $100 \mathrm{~km}$, and decreased to $2 \times 10^{5}$ at $110 \mathrm{~km}$, $2 \times 10^{4}$ at $120 \mathrm{~km}$ and 0 above $120 \mathrm{~km}$ (US Standard Atmosphere, 1976). Expressions for the neutral molecular diffusion coefficient and ion-neutral, neutral-ion and ion-ion collision frequencies were obtained from Banks and Kockarts (1973), and neutral temperatures 

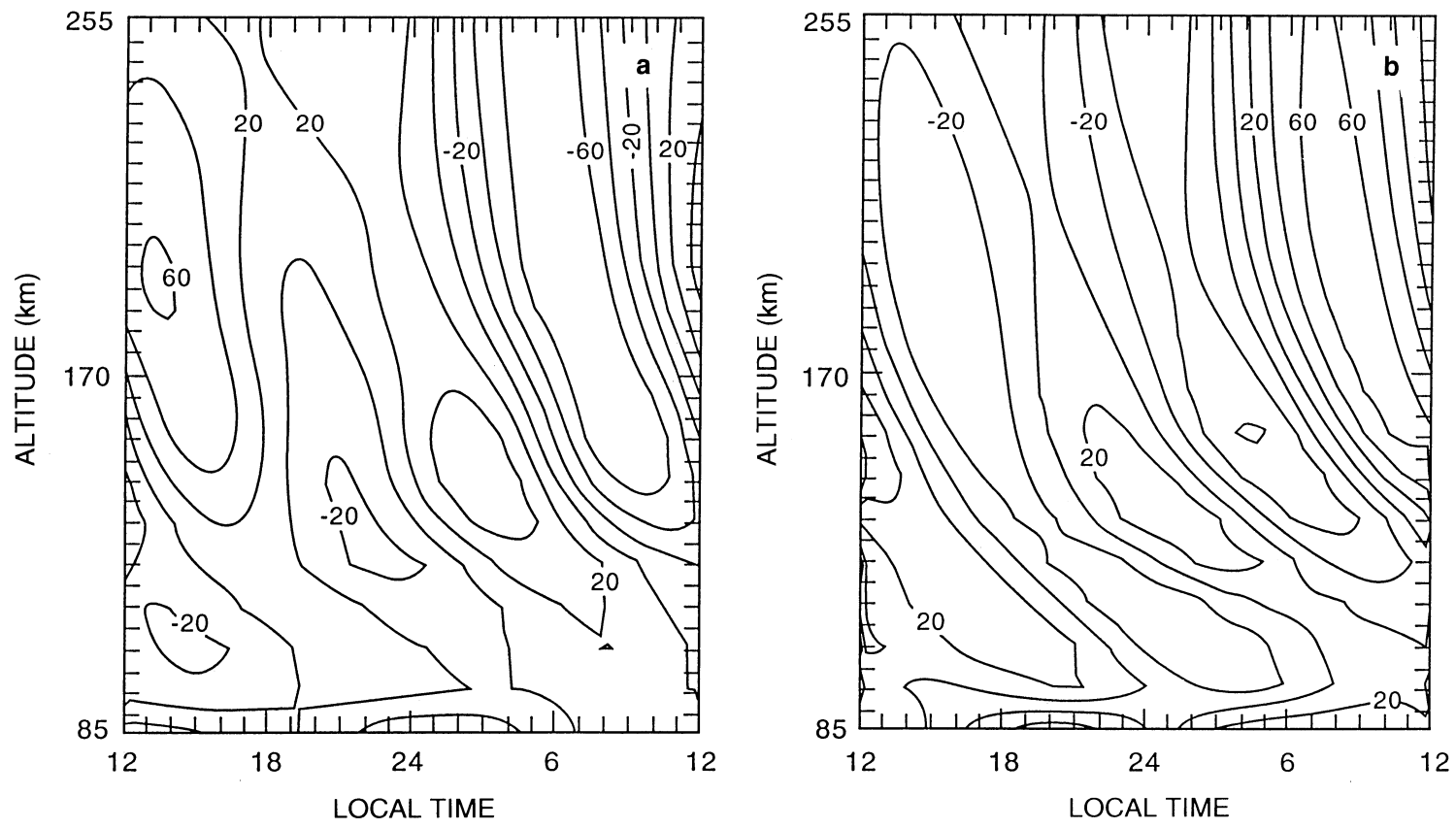

Fig. 3a, b. Height versus local time structures of a zonal wind and $\mathbf{b}$ meridional wind at $18^{\circ}$ latitude

and composition were from the MSISE90 model (Hedin, 1991). Geophysical conditions were set to be vernal equinox, moderate solar activity $(\mathrm{F} 10.7=120)$ and quiet geomagnetic activity $(\mathrm{Ap}=10)$. Quiet-time electric fields were specified according to the empirical model of Richmond et al. (1980). The 1990 International Reference Ionosphere (IRI-90; Bilitza, 1990) was used to specify the ambient ionospheric composition $\left(\mathrm{O}^{+}, \mathrm{O}_{2}^{+}\right.$, $\mathrm{NO}^{+}$). Since IRI-90 only extends to $1800 \mathrm{~km}$, a simple plasmasphere model based on Gallagher et al. (1988) was used to reflect non-zero plasma density in this outer region.

\subsection{Transport formulation}

In the case of $\mathrm{Fe}^{+}$, the transport velocity in Eq. (1) is the ion drift velocity given by

$\vec{v}_{i}=\frac{1}{\kappa^{3}+\kappa}\left(\kappa^{2} \overrightarrow{\mathbf{F}}+\kappa \overrightarrow{\mathbf{F}} \times \vec{\Gamma}+(\vec{\Gamma} \cdot \overrightarrow{\mathbf{F}}) \vec{\Gamma}\right)$

where the function $\overrightarrow{\mathbf{F}}$ (units of velocity) is defined as

$\overrightarrow{\mathbf{F}}=\kappa \vec{u}+(1 / \Omega) \vec{g}-\kappa(D / n) \vec{\nabla} n+\vec{E}_{B}$

and

$\kappa=v / \Omega$

$\Omega=\mathrm{Fe}^{+}$ion gyrofrequency

$v=$ ion-neutral collision frequency

$\vec{\Gamma}=\vec{B} / B$

$\vec{B}=$ ambient magnetic field vector; $B=|\vec{B}|$

$\vec{E}=$ electric field vector; $\vec{E}_{B}=\vec{E} / B$

$\vec{g}=$ acceleration due to gravity

$D=$ diffusion coefficient

$n=$ number density of $\mathrm{Fe}^{+}$

For $\mathrm{Fe}$, the transport velocity is just $\vec{v}_{n}=\vec{u}+\vec{g} / v-(D / n) \vec{\nabla} n$

where $\vec{u}$ is the ambient neutral wind vector. From Eqs. (2) and (3) the low- and high-altitude limiting cases and the separate effects of each component are easy to see. At low altitudes $\kappa \gg 1$, so the expression is dominated by terms cubic in $\kappa$, leaving only the neutral wind term of (4) (since $D \propto 1 / v=1 / \Omega \kappa$, the gradient term is only quadratic in $\kappa$ ). Thus at low altitudes neutral flow dominates and $\vec{v}_{i} \cong \vec{u}$. At very high altitudes $\kappa \ll 1$ and the dominant term becomes $(\vec{\Gamma} \cdot \overrightarrow{\mathbf{F}}) \vec{\Gamma}$, with $\vec{F}$ dominated by $\vec{g} / \Omega$ and $\vec{E}_{B}$, that is, in a collisionless regime motion is dominated by $\vec{E}$ and $\vec{B}$, and an ion will drift to Earth following the local geomagnetic field line and will drift at $\vec{E} \times \vec{B} / B^{2}$. For the intermediate case $\kappa \cong 1$ (130 to $140 \mathrm{~km})$ so that all terms are non-negligible. The resulting ion motion in this regime is a complicated vector sum of all four forces, each generating motion along $\overrightarrow{\mathbf{F}}$, along the $\vec{F} \times \vec{B}$ axis, and along $\vec{B}$.

The component of the transport velocity which gives rise to ion layering is the vertical ion drift, $w_{i}$. Figure 4 illustrates the height versus local time distributions of the vertical ion drifts at $18^{\circ} \mathrm{N}$ due to (a) the meridional wind; (b) the zonal wind; (c) the electric field; and (d) all three of the previous components together. Careful inspection shows that both the meridional and zonal winds possess a p.m. diverging null followed by a converging null, and the same null pair for the a.m. sector. The strong influence of the semidiurnal tide is particularly evident. It is interesting to note that within the E-region, a zonal neutral wind by itself can actually give rise to a vertical ion drift, and even a descending convergent null in the vertical ion drift distribution. Moreover, the vertical ion drifts due to the zonal wind tend to maximize near $130-140 \mathrm{~km}$ and extend down to $110 \mathrm{~km}$, whereas ion drifts due to the meridional wind 

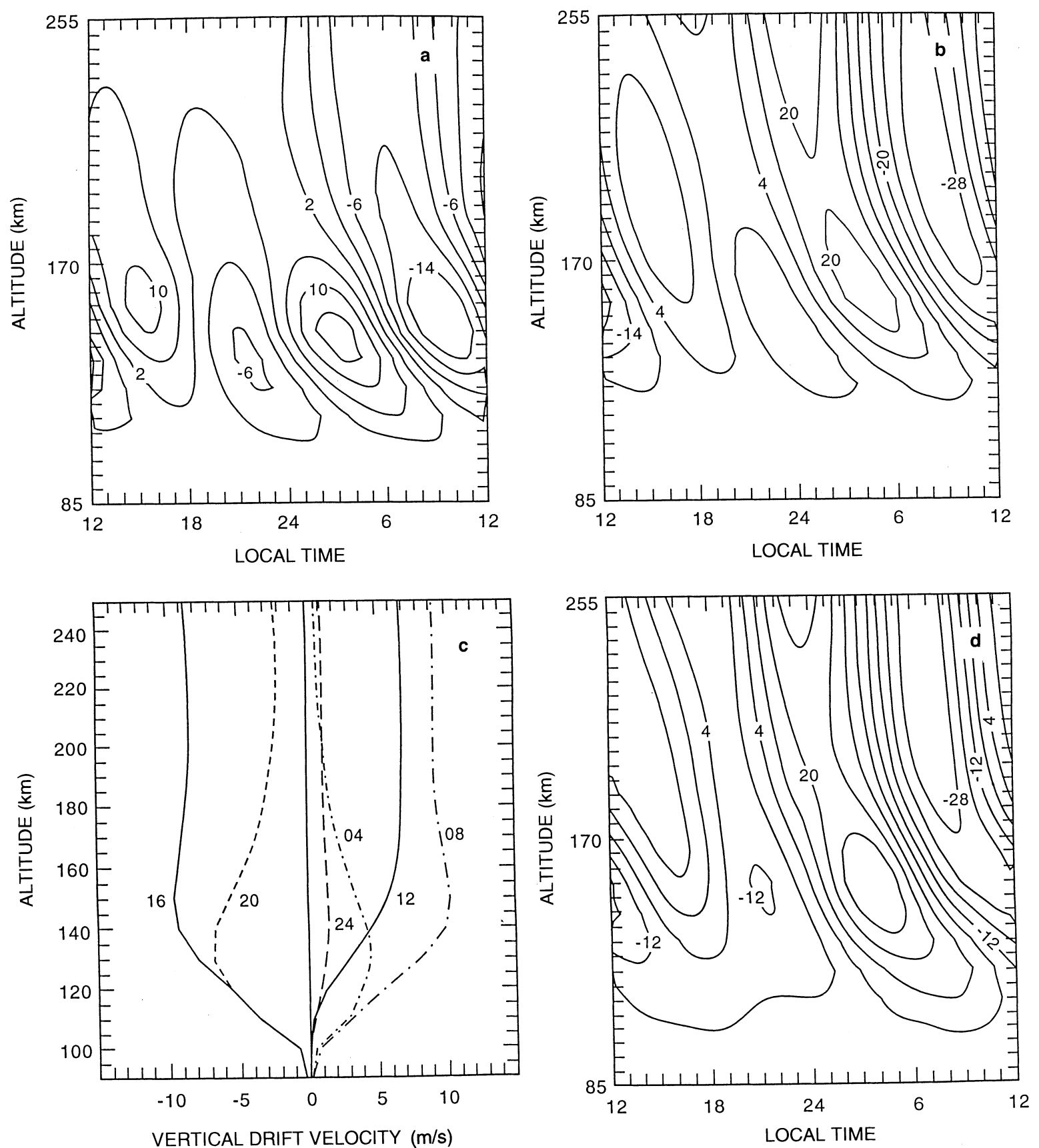

Fig. 4a-d. Vertical ion drifts at $18^{\circ}$ latitude due to a zonal wind; $\mathbf{b}$ meridional wind; $\mathbf{c}$ electric field; $\mathbf{d}$ the combination of $\mathbf{a}, \mathbf{b}$ and $\mathbf{c}$

tend to occur about $20 \mathrm{~km}$ higher in altitude. Electric field-driven drifts at $18^{\circ} \mathrm{N}$, according to the "smoothed" empirical model of Richmond et al. (1980), tend to be upward between 0000 LT and 1200 LT, and downward otherwise.

\section{Results}

\subsection{Localized layering}

The objectives of this section are to develop an understanding of the effects of those transport processes leading to ion layering, to describe in a quantitative sense how local transport at low and medium altitudes affects metallic ion distributions, and to graphically display the interdependence and interaction of these processes, and their effects on metallic ions, as they evolve over time. Although metallic ion layering is a well-known and thoroughly investigated phenomenon, numerical models have thus far reproduced in only a qualitative, or at best, semi-quantitative, sense the critical cause-effect relationships affecting local ion transport. In particular the separate and combined effects of meridional winds, zonal winds, electric fields, and meteoric deposition profile on the collective behavior of metallics have been issues in need of elucidation and clarification. The simulations discussed below are 
intended to shed new light on the cause-effect linkage and on the evolution, over a diurnal cycle, of these processes and the ion distributions throughout the $\mathrm{E}$ region and the "valley" region above.

The following results are from the 1-D version of the model, with model parameters fixed at the location of Arecibo $\left(18^{\circ} \mathrm{N}, 67^{\circ} \mathrm{W}\right.$ geographic; $30^{\circ} \mathrm{N}, 2^{\circ} \mathrm{E}$ geomagnetic), with prevailing conditions of geomagnetic quiet, moderate solar activity, and vernal equinox $(\mathrm{F} 10.7=120$ and $\mathrm{Ap}=10)$. Model results are displayed as contour plots in units of $\log _{10}\left[\mathrm{Fe}^{+}\right]$with $\left[\mathrm{Fe}^{+}\right]$ in $\mathrm{m}^{-3}$, covering a full noon-to-noon diurnal cycle and a height range of 90 to $250 \mathrm{~km}$. The altitude resolution (cell height) is set to $1.0 \mathrm{~km}$, and the temporal resolution between data points is $600 \mathrm{~s}$. The contours are spaced at one-quarter order of magnitude in density; absolute magnitudes of metallic ion densities range from a preselected minimum of $6.0\left(10^{6}\right.$ ions $\mathrm{m}^{-3}$ or $\left.1 \mathrm{~cm}^{-3}\right)$ to 11 $\left(10^{11} \mathrm{~m}^{-3}\right)$ for descending layer peaks.

No wind, with electric field. As shown in Fig. 4c, the vertical component of the electric field-driven drift is positive throughout the daylight morning sector, peaking in the late a.m. sector, and then rapidly decreasing to zero by 1400 . The corresponding model response is a strong upward transport which sweeps out ions in the intermediate (130 to $220 \mathrm{~km}$ ) region, forming the valley centered at $1400 \mathrm{LT}$ and $160 \mathrm{~km}$ (see Fig. 5). After reversing direction at 1400 , the flow speed increases until about 1900 LT, causing a descending ridge of density to appear in the 1500-1900 LT sector, with a break in the peak contour due to the bulk motion of downwardflowing ions. This downward flow rate decreases after

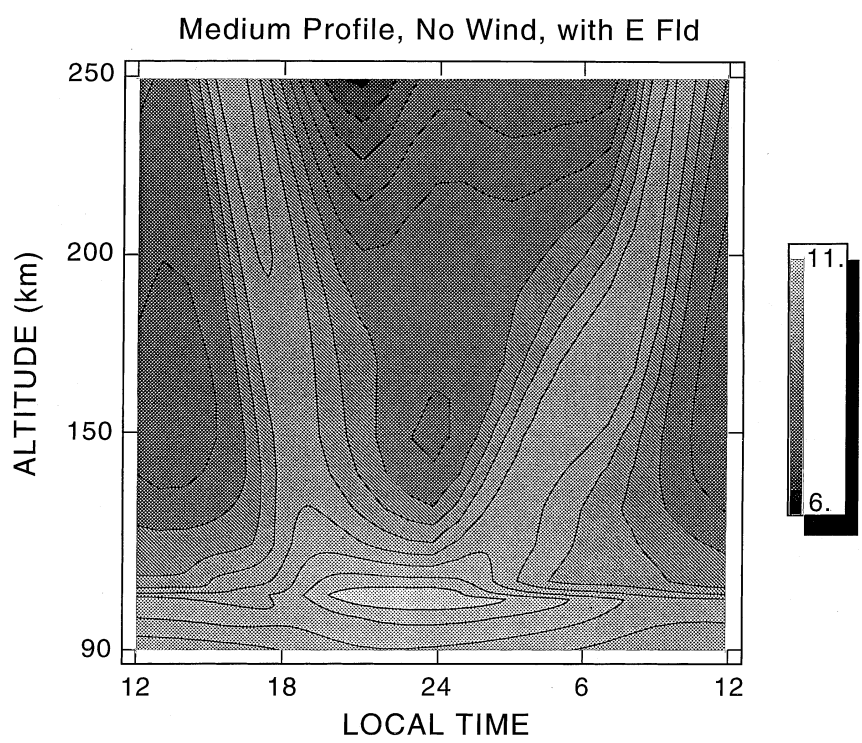

Fig. 5. Height versus local time contours of $\log _{10}\left[\mathrm{Fe}^{+}\right]$at $18^{\circ}$ latitude from the $1-\mathrm{D}$ version of the model, and driven by vertical drifts due to the electric field only. Minimum contour is 6.0 (black) and maximum contour is 12.0 (white), with spacing of 0.25 and concentrations given in $\mathrm{m}^{-3}$
1900 with the formation of a weak divergent null after 2200 LT that lasts until midnight, with the null point dropping in altitude during that time. The corresponding ion behavior consists of formation of a long deep valley centered at midnight, since a divergent null will transport ions both upward and downward away from the valley's central region. The combination of downward motion and meteoric deposition causes the diurnal peak of $2.14 \times 10^{10} \mathrm{~m}^{-3}$ to occur just prior to midnight at $105 \mathrm{~km}$. Progressing to the morning sector the E-field induced velocity is upward at all altitudes, initially at low levels $(100$ to $160 \mathrm{~km})$, then expanding to strong upward flow all the way to $300 \mathrm{~km}$ by $0900 \mathrm{LT}$. The ions first accumulate at $110 \mathrm{~km}$ in the early a.m. sector and later form an upward-directed gradient, becoming a ridge-like peak at $160-200 \mathrm{~km}$ by 0600 LT. With the maximum of the upward motion reached by about $1100 \mathrm{LT}$, a valley begins to appear over the 130 to $200 \mathrm{~km}$ region by local noon, at which point the next diurnal cycle begins, repeating the pattern on the extreme left.

Zonal wind, no electric field. The behavior of metallic ions in the presence of a wind field is affected primarily by convergent and divergent nulls in the field, since those are points of ion flow reversal. The time history of the zonal wind (Fig. 3) and the associated ion vertical velocity (Fig. 4a) show a divergent null in the ion motion starting at $190 \mathrm{~km} / 100 \mathrm{LT}$ which first builds in strength and then drops, finally dissipating at $1600 \mathrm{LT}$; the effect on the ions is a spreading-out over the 150 to $200 \mathrm{~km}$ region, leading to an upward-directed flow of $\mathrm{Fe}^{+}$in the $1400-1600$ LT sector as shown on Fig. 6a (left panel). Cessation of upward flow at 1900 LT leads to a broad gentle peak at about $170 \mathrm{~km}$, with the density above this peak either growing very slowly or decreasing. The late night sector is characterized by weak downward flow in the lower altitudes causing tightened downward-directed contours, with the ions piling up along a ridge at about $120 \mathrm{~km}$. At $2200 \mathrm{LT}$ a weak divergent null forms in the wind field and descends from 170 to $110 \mathrm{~km}$ by $0400 \mathrm{LT}$, the net effect being to further compress the $\mathrm{Fe}^{+}$contours just below the null. This divergent null leaves behind a valley centered at 0200 LT/135 km, with a further buildup of the bottomside ridge that peaks at $4.9 \times 10^{10} \mathrm{~m}^{-3} / 105 \mathrm{~km}$. The increase above $135 \mathrm{~km}$ is due to the upward wind motion which tapers off at higher altitudes, so that density decreases above $200 \mathrm{~km}$. Finally, a convergent null appears at $0200 \mathrm{LT}$ and $190 \mathrm{~km}$, becoming stronger and lower with time, finally tapering off to a weak null by 1000 LT. The resultant effect on $\mathrm{Fe}^{+}$is the generation of a steadily growing descending layer which first appears at 0300 LT, later settling out and stabilizing by $1200 \mathrm{LT}$; the diurnal peak of $9.1 \times 10^{10} \mathrm{~m}^{-3}$ occurs within this layer at 1300 LT. An additional effect of this null is the steep gradient just above the descending layer, resulting in a depletion region of ions centered at 1100 LT and $175 \mathrm{~km}$, as the descending null "sweeps out" ions in its path. 

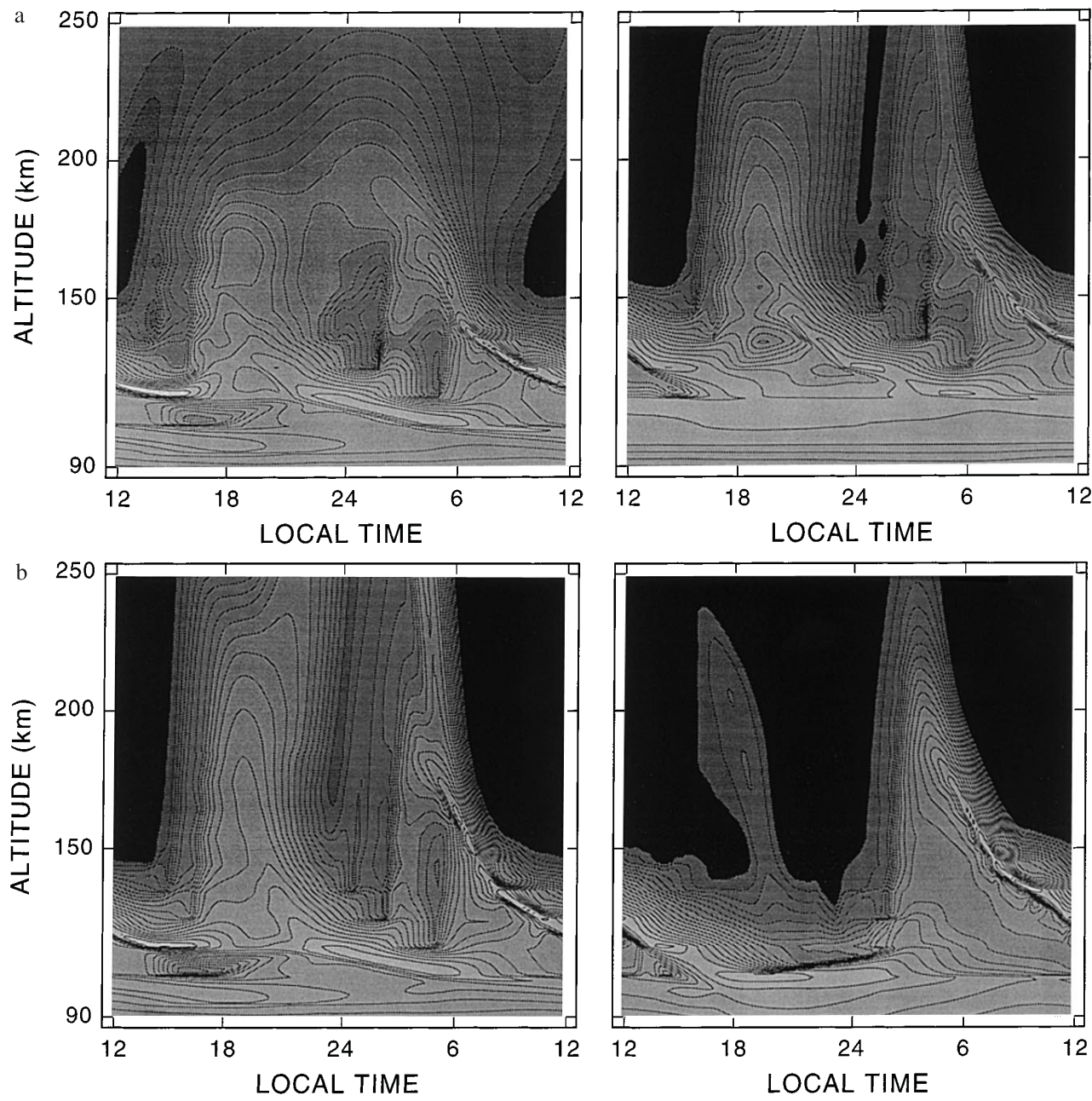

Fig. 6a. (top panels) Height versus local time contours of $\log _{10}\left[\mathrm{Fe}^{+}\right]$at $18^{\circ}$ latitude from the 1-D version of the model, and driven by vertical drifts due to zonal winds only (left panel) and meridional winds only (right panel). Minimum contour is 6.0 (black) and maximum contour is 12.0 (white), with spacing 0.25 and concentrations given in $\mathrm{m}^{-3}$. b (bottom panels) Height versus local time contours of $\log _{10}\left[\mathrm{Fe}^{+}\right]$at $18^{\circ}$ latitude from the $1-\mathrm{D}$ version of the model, and driven by vertical drifts due to zonal and meridional winds (left panel) and electric fields in addition to zonal and meridional winds (right panel) others details as in $\mathbf{a}$
Meridional wind, no electric field. The meridional field of Fig. 3 (wind) and Fig. 4b (vertical ion velocity) show predominantly downward flow at 1200 LT below $200 \mathrm{~km}$, peaking at $150 \mathrm{~km}$, with the strength and altitude of the peak gradually decreasing through the p.m. sector. Over the same period, a divergent null forms at high altitude and progresses downward, dropping to $175 \mathrm{~km}$ at $1300 \mathrm{LT}$ and to $125 \mathrm{~km}$ at 1800 LT. The resultant $\left[\mathrm{Fe}^{+}\right]$pattern displayed in Fig. 6a (right panel) is a series of similar-shape contours characterized by a horizontal gradient which abruptly changes to almost vertical at the location of the null. Thus, downward flow below the null maintains the $\left[\mathrm{Fe}^{+}\right]$level through time, whereas upward flow above results in a rapid density increase throughout a broad altitude region. This phase of the wind field is followed by a convergent null which begins at about 1930 LT and $160 \mathrm{~km}$, subsequently collapsing and initially dropping rapidly, then dropping more slowly after 2400 LT to below $120 \mathrm{~km}$. The ions respond by forming an enhanced level of $\mathrm{Fe}^{+}$which descends with the null and develops into a narrow layer at about $2100 \mathrm{LT} /$ $140 \mathrm{~km}$, later settling out and stabilizing through the nighttime sector. This convergent null is followed by a second divergent null starting at $2100 \mathrm{LT}$ and continuing through the night, dropping from $200 \mathrm{~km}$ initially to
$160 \mathrm{~km}$ at midnight and then to $130 \mathrm{~km}$ at $0500 \mathrm{LT}$, thereby generating a descending pattern of backward-L contours similar to the early morning divergent null. The periodic compression and flattening of the gradient in this region appears due to rapid changes in the strength and profile of the wind field, forming localized minima which are slowly "refilled" by upward ion migration. Finally, a strong convergent null forms at $0500 \mathrm{LT} / 185 \mathrm{~km}$, dropping and intensifying throughout the pre-noon sector to $1200 \mathrm{LT} / 125 \mathrm{~km}$ with a corresponding increase in downward-directed flow. The overall ion migration result is the strong descending and rapidly intensifying layer displayed on the right side of Fig. 6a (right panel), with peak density at $4.8 \times 10^{10} \mathrm{~m}^{-3}$.

Meridional and zonal winds, no electric field. As might be expected, the $\left[\mathrm{Fe}^{+}\right]$pattern for this case is a combination, of superposition, of the first two; in fact, it is a rather unique form of superposition. Referring back to Eq. (2), the second term describes the effect of a zonal wind on $\vec{v}_{i}$ and the third the effect of a meridional wind (the first term vanishes in the absence of a vertical wind). These two terms have different altitude dependencies since the second is weighted by $\kappa$ and the third is not. Therefore, at low altitudes of $130 \mathrm{~km}$ or less $(\kappa>1)$, the 
zonal wind will have increased influence; at high altitudes $(\kappa<1)$, the meridional wind will dominate. Inspection of Fig. 6b (left panel) shows just this type of behavior: comparing and contrasting with Fig. 6a (meridional wind only, right panel; zonal wind only, left panel), it is easy to see that the low altitude structure (below $120 \mathrm{~km}$ ) in the left panel of Fig. 6b is much more similar to the "zonal wind only" than to "meridional wind only", whereas at high altitudes (above $140 \mathrm{~km}$ ) just the reverse is true. This serves to illustrate the complex effects a realistic wind field has on metallic ion dynamics. This case had the highest metallic ion density of all five at $1.02 \times 10^{11} \mathrm{~m}^{-3}$ located at $1500 \mathrm{LT} /$ $115 \mathrm{~km}$, within the stagnation phase of the a.m. descending layer.

Meridional and zonal winds, with electric field. With the full wind plus the E-field in effect (right panel, Fig. 6b), comparison (left panel, Fig. 6b) illustrates that winds are the dominant transport mechanism. However, Efield induced upward migration in the a.m. sector results in a morning descending layer of slightly increased density since a greater number of ions are now available for "capture" by the convergent null, while the midnighttime valley of the wind-only case is considerably deepened by downward migration due to the E-field. This high altitude depletion (above $150 \mathrm{~km}$ ) throughout most of the nighttime sector is clearly the one major effect of adding E-field to the full-wind case, due to the combination of early p.m. downward flow followed by divergent null. This effect can be explained to some extent by the physics which governs the relative dependencies, as given by Eq. (3): Specifically, the first and last terms for the forcing function $\vec{F}, \kappa \vec{u}$ and $\vec{E}_{B}$, show that $\vec{E}_{B}$ dominates over $\vec{u}$ at high altitudes, but the effects of winds increase as altitude decreases ( $\kappa$ transitions from $<1$ to $>1$ at about $140 \mathrm{~km}$ ).

Meridional and zonal winds, with electric field, using low altitude and high altitude deposition profiles. Although not illustrated here, changing the altitude profile of the metallic deposition through the meteor ablation had the following effects: while the low-altitude portion (below $130 \mathrm{~km}$ ) changes very little, the higher altitude region was considerably affected by changes in ion density. The high-altitude source profile exhibits the greatest concentration levels, the medium-altitude profile is intermediate, and the low-altitude source profile had the lowest contour levels. In fact, the peak contour levels (in units of $\log _{10}\left[\mathrm{Fe}^{+}\right]$) in the evening descending layer differ considerably at $7.25,6.5$, and 6.0 , with corresponding peak diurnal values of $7.9,5.5$, and $3.9 \times 10^{10} \mathrm{~m}^{-3}$, all within the last stage of the morning layer. This variation is due to the gradual downward migration of ions following ablation and photoconversion; the higher the ablation profile, the more effective will be the descending convergent null in trapping and accumulating metallic ions. The considerable overlap between the altitude region of the convergent nulls and that of the deposition process reinforces this linkage.

Total plasma density. Figure $7 \mathrm{a}, \mathrm{b}$ provides a different perspective, each representing the sum of both the metallic and ambient ion density components. The illustrated curves represent vertical profiles from the same simulation at selected times, to illustrate the development of metallic layers contrasted against the ambient background. Indeed, radar measurements from the ground only "see" the total plasma density, so it is important to illustrate in this fashion that the
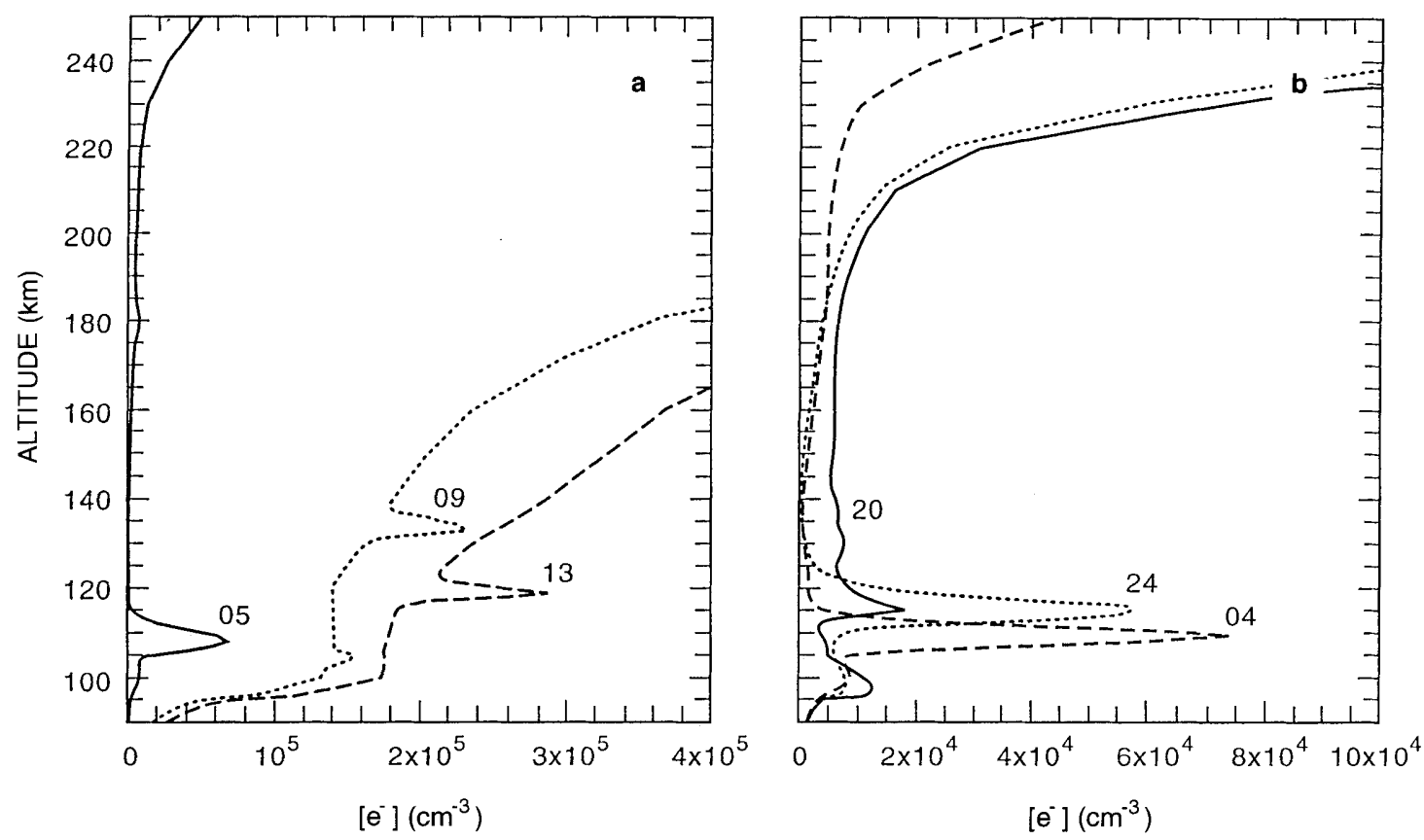

Fig. 7a, b. Vertical profiles of total plasma density, showing evolution of a the morning descending layer and $\mathbf{b}$ the evening descending layer. Curves and labeled with local times 
numerical simulations are capable of achieving significant localized enhancements in the total plasma density, even during daytime. The evening layer can be seen starting at $2100 \mathrm{LT}$ and $140 \mathrm{~km}$, dropping to $110 \mathrm{~km}$ by $0500 \mathrm{LT}$; the morning layer commences at $0400 \mathrm{LT} /$ $180 \mathrm{~km}$, stabilizing at $115 \mathrm{~km}$ by $1400 \mathrm{LT}$. One feature worthy of comment is the relative strength, persistence, and merging of the morning and evening layers in the terminal stagnation phase, when layer descent rate is at or near zero (about $115 \mathrm{~km}$ ).

Model results compared to observations. The nighttime layers seen here can be compared to layers observed over Arecibo during the AIDA-89 campaign (Kane et al., 1993). Their Figs. 3 and 4 illustrate several cases of plasma layers detected by the Arecibo ISR from 2138 to 0200 LT, 30-31 March 1989. Of the eight ion layers shown, the altitudes ranged from $95 \mathrm{~km}$ to $103.5 \mathrm{~km}$ with an average of $100 \mathrm{~km}$. Simulation results from Fig. 6b show layers from 98 to $116 \mathrm{~km}$ with an average of $110 \mathrm{~km}$. Likewise, the peak electron density from the AIDA results ranged from $6.5 \times 10^{9} \mathrm{~m}^{-3}$ to $3.2 \times 10^{10} \mathrm{~m}^{-3}$ and averaged $1.8 \times 10^{10} \mathrm{~m}^{-3}$; the simulation layers in Fig. $6 \mathrm{~b}$ had extremes of $1.16 \times 10^{10} \mathrm{~m}^{-3}$ and $7.5 \times 10^{10} \mathrm{~m}^{-3}$, averaging $4.1 \times 10^{10} \mathrm{~m}^{-3}$. Defining layer thickness as full width at half maximum (FWHM), the AIDA thicknesses were one to five $\mathrm{km}$ with the average at $1.8 \mathrm{~km}$, whereas the model values were 4.5 to $9.4 \mathrm{~km}$, with an average of $6.6 \mathrm{~km}$. It is believed that this difference in layer thickness is due partly to the detailed dynamics of actual wind fields not incorporated in the model.

\subsection{Global transport}

This subsection is devoted to a description of numerical simulations using the two-dimensional (meridional plane) version of the model. We begin with a description of the system response to electric fields alone, to elucidate the salient features of global ion transport driven by this mechanism. The subsequent subsection considers the additional effects of neutral winds on the latitude/height/local time distribution of $\mathrm{Fe}^{+}$. With local time as one dependent variable, $\mathrm{Fe}^{+}$distributions are available as a function of latitude $\left(0^{\circ}\right.$ to $\left.45^{\circ}\right)$ at reference altitudes of 100,200 and $300 \mathrm{~km}$, and as a function of latitude at reference latitudes of $6^{\circ}, 22.5^{\circ}$ and $36^{\circ}$. Comparisons with results described in Sect. 3.1 are provided throughout. The reader is referred to Carter (1995) for a discussion of simulation results above $300 \mathrm{~km}$.

Electric field effects. In the meridional plane, the vertical drifts induced by electric fields in the F-region (i.e., the vertical component of $\vec{E} \times \vec{B} / B^{2}$ ) are strongly dependent on latitude; due to the decrease in $\vec{B}$ field strength and the increasing inclination of $\vec{B}$ with latitude, the vertical drift velocity decreases markedly in the poleward direction, varying by roughly a factor of three over the latitudinal extent covered. Moreover, at low latitudes the vertical drift is upward by day and downward by night. This upward daytime flow, combined with poleward meridional transport and eventual downward diffusion, leads to a redistribution of plasma referred to as the "fountain effect". Thus, we expect to see strong signatures of this behavior in the $\mathrm{Fe}^{+}$densities.

Figure 8 illustrates the latitude/local time distributions of $\log _{10}\left[\mathrm{Fe}^{+}\right]$at 100,200 and $300 \mathrm{~km}$ when the transport in the model is due to electric fields alone. At all three altitudes the tendency is for greater $\mathrm{Fe}^{+}$ densities at higher latitudes, despite the fact that meteoric deposition and production of $\mathrm{Fe}^{+}$via charge exchange are maximum at the equator. The upward/ poleward/downward circulation of the fountain effect yields the greatest ion densities at the highest latitudes. The effects at lower altitudes are of course less pronounced, since local meteoric deposition and photo-
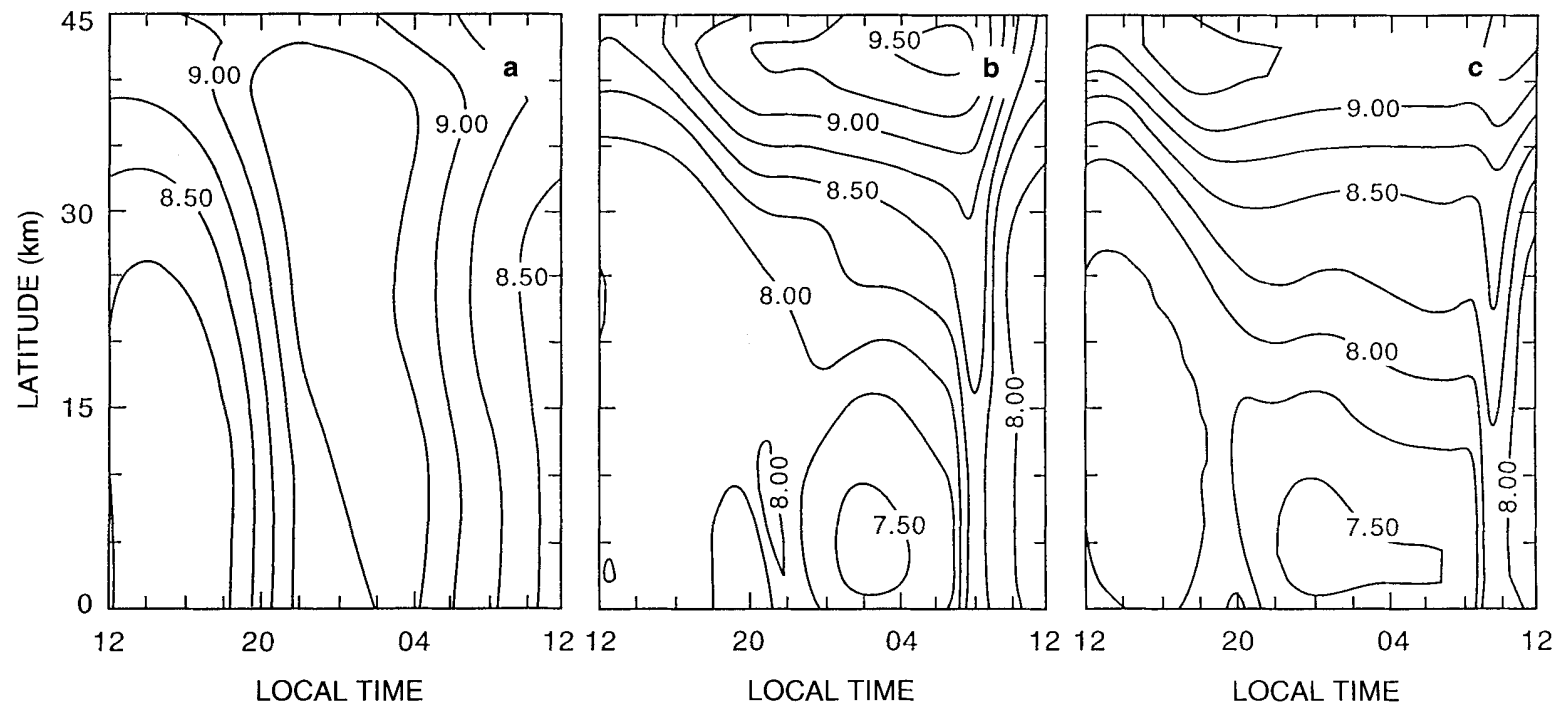

Fig. 8a-c. Latitude versus local time contours of $\log _{10}\left[\mathrm{Fe}^{+}\right]$due to electric field transport only, at altitudes of a $100 \mathrm{~km} ; \mathbf{b} 200 \mathrm{~km}$; $300 \mathrm{~km}$ 
conversion of freshly ablated Fe dominate as the local source of $\mathrm{Fe}^{+}$, in comparison to downward transport from above. We note that as one goes to higher altitudes (>about $600-700 \mathrm{~km}$ ), this trend reverses, and maximum densities are found at the equator (see Carter, 1995), in agreement with satellite observations (Kumar and Hanson, 1980; Grebowsky and Reese, 1989).

It is interesting to compare Fig. 8 with Fig. 9, which illustrates the $\log _{10}\left[\mathrm{Fe}^{+}\right]$distributions at 100,200 and $300 \mathrm{~km}$ in the presence of winds, but no electric field. Here the maximum densities at $200 \mathrm{~km}$ and above are 23 orders of magnitude smaller than with electric fields alone, which obviously serve as the primary agent for populating the F-region with metallic ions. Moreover, the tendency in Fig. 9 is for maximum densities above $200 \mathrm{~km}$ to occur at low latitudes, where the source of $\mathrm{Fe}^{+}$is greatest, and to redistribute the $\mathrm{Fe}^{+}$upward and poleward so as to form the "fingers" near 1800-2000 LT and 0400-0600 LT. While these features obviously represent signatures of the semidiurnal tide on the redistribution of $\mathrm{Fe}^{+}$, it is not immediately clear what the relative roles of zonal and meridional winds are in creating these structures. For instance, zonal winds near $150 \mathrm{~km}$ can either drive ions to lower or higher altitudes (see Fig. 4); the degree to which this effective ion source leads to meridional redistributions of ions depends on the relative phase of the meridional wind at the capturing point. Moreover, through dependencies on the B-field in Eq. (2), the relative effectiveness of zonal winds (through the $\vec{u} \times \vec{B}$ force) and meridional winds (through the $(\vec{u} \cdot \vec{B}) \vec{B}$ force) in vertical redistribution vary with latitude, the former being more important at low latitudes where the B-field is quasi-horizontal. On the other hand, F-region meridional winds will be more effective in transporting ions horizontally at low latitudes. The key point is, that the "fingers" especially evident in Fig. 9c are not totally a result of meridional transport (as might appear at first), but represent some combination of vertical and meridional transport effects which are latitude dependent. The interested reader is referred to Carter (1995) for more specific details of the individual effects of zonal and meridional winds on global metallic ion distributions.

Winds and electric fields. Further insight into metallic ion transport is provided by Fig. 10, which illustrates the height versus local time distributions of vertical ion drift (Fig. 10a) and $\log _{10}\left[\mathrm{Fe}^{+}\right]$at $9^{\circ}$ latitude (Fig. 10b), taking into account transport by zonal and meridional winds, and electric fields. The total vertical ion drifts between 120 and $160 \mathrm{~km}$ consist of downward drifts $\left(\sim 10-40 \mathrm{~ms}^{-1}\right)$ between about $1800 \mathrm{LT}$ and $0200 \mathrm{LT}$ and upward drifts $\left(\sim 10-20 \mathrm{~ms}^{-1}\right)$ at other times, with relatively little downward phase progression. Vertical velocities are small below $115 \mathrm{~km}$. Referring to Fig. 10b, the upward drifts between 1200 and 1700 LT sweep the ions upward, resulting in sharply downward-sloped density contours as each altitude becomes progressively more ion-depleted. As the drift turns downward around 1800 LT, a wide descending layer narrows into a more typical layer near $103-106 \mathrm{~km}$ with density of $2.2 \times 10^{10} \mathrm{~m}^{-3}(\log$ density $=10.35)$. This morning (0400-0600 LT) layer formation is due to a rapid reduction in downward motion, resulting in an accumulation of ions descending from above.

After 0400 LT the vertical drift shifts from downward to upward, although remaining very small below $120 \mathrm{~km}$. This reversal halts downward ion migration and initiates upward flow, resulting in quasi-horizontal contours below a density "valley" followed by vertical contours, as the dense, low-lying region is depopulated, forcing ions upward into a much more rarified zone. The density maximum near $160 \mathrm{~km}$ at $0800 \mathrm{LT}$ is connected with the convergent null of similar shape (see Fig. 10a) in the vertical drift, but also receives some contribution from poleward transport from the source region (Fig. 9b).

Figure 11 is the same as Fig. 10, except for $22.5^{\circ}$ latitude where the neutral wind magnitudes are the
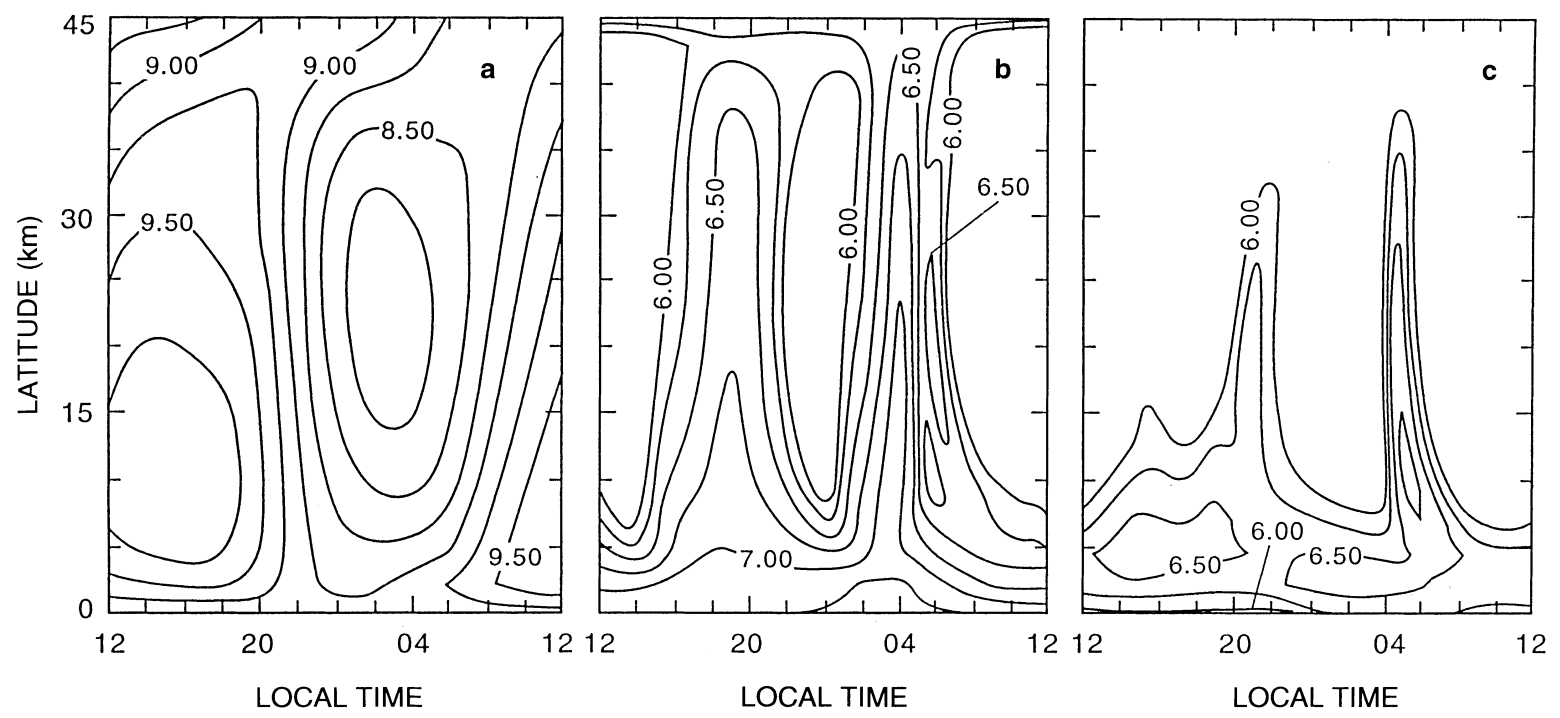

Fig. 9a-c. Same as Fig. 8, except due to transport by zonal and meridional winds (no electric field) 

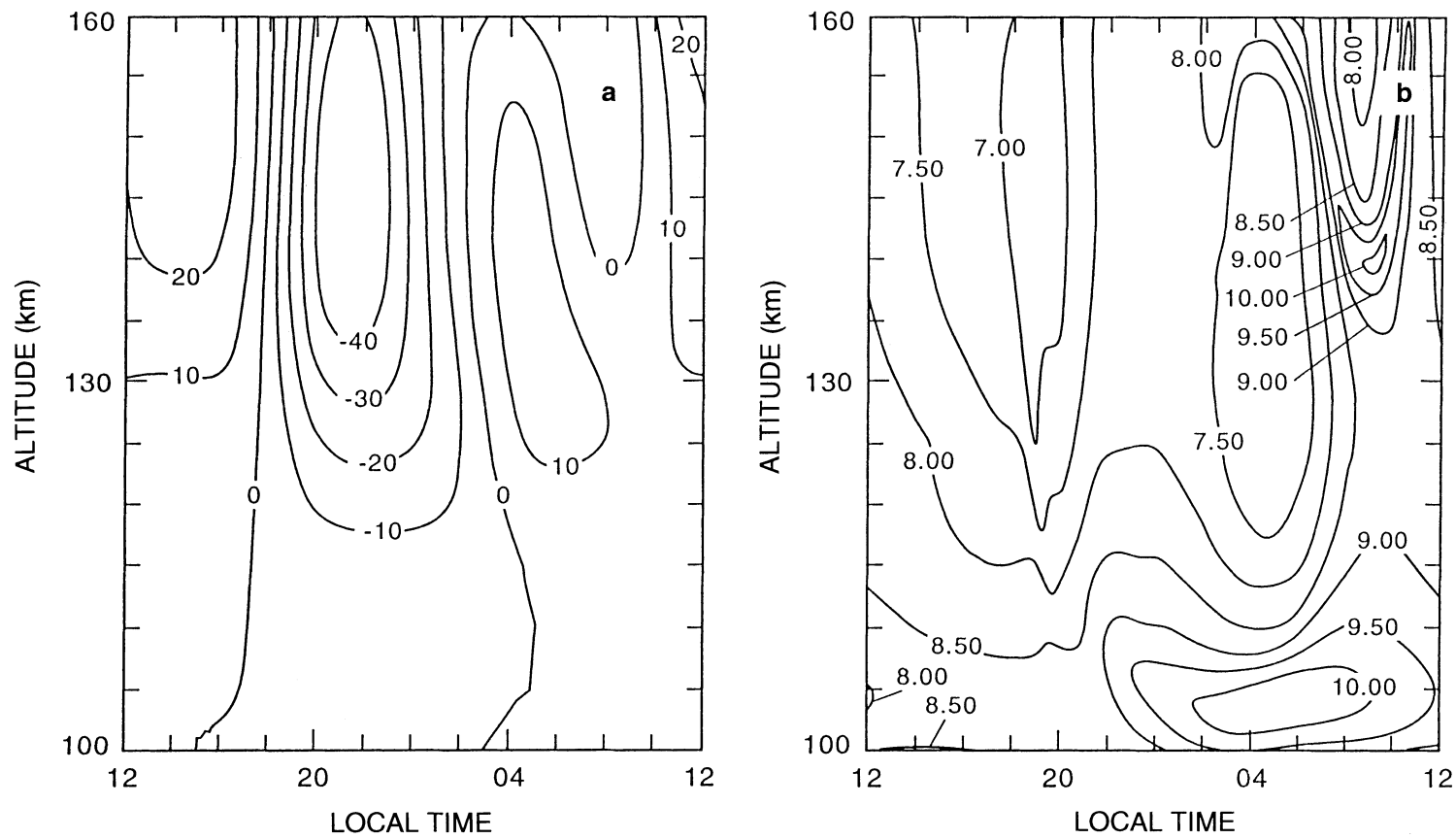

Fig. 10.a Height versus latitude contours of vertical ion drift at $9^{\circ}$ latitude due to zonal and meridional winds and electric field. b The corresponding contours of $\log _{10}\left[\mathrm{Fe}^{+}\right]$

largest. Here the vertical ion drifts (Fig. 11a) take on the semidiurnal character of the wind field. The density maximum which occurred near $160 \mathrm{~km}$ near $0800 \mathrm{LT}$ at $9^{\circ}$ latitude (Fig. 10b) now appears as a more concentrated descending layer extending down to $105-110 \mathrm{~km}$ around $1600 \mathrm{LT}$, reaching maximum densities of order $10^{10} \mathrm{~cm}^{-3}$. This descending layer merges into a low-lying post-midnight layer similar in character to that displayed in Fig. $10 \mathrm{~b}$ for $9^{\circ}$ latitude. Both of these layers are the result of the net downward transport beginning near $1800 \mathrm{LT}$ that is common to both latitudes. Note that at $22.5^{\circ}$ latitude there exist two divergent nulls extending downward from $160 \mathrm{~km}$ near $1800 \mathrm{LT}$ and 2400 LT (Fig. 11a); both of these are accompanied by significant depletions (down to $10^{6} \mathrm{~cm}^{-3}$ ) in the ion densities near these times (Fig. 11b).

Finally, Fig. 12 illustrates the latitude/local-time distributions of $\log _{10}\left[\mathrm{Fe}^{+}\right]$due to zonal and meridional
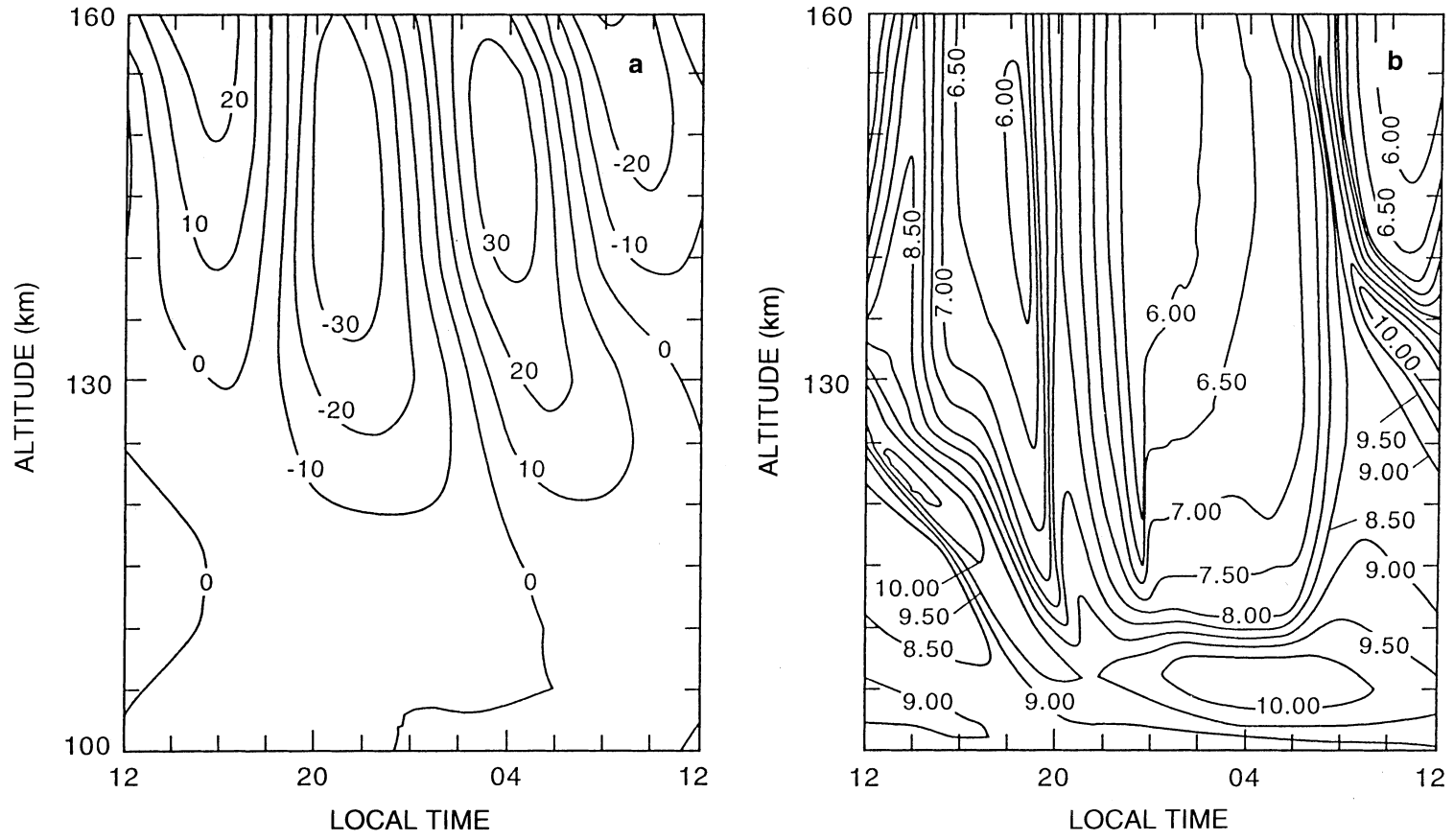

Fig. 11a, b. Same as Fig. 10, except at $22.5^{\circ}$ latitude 

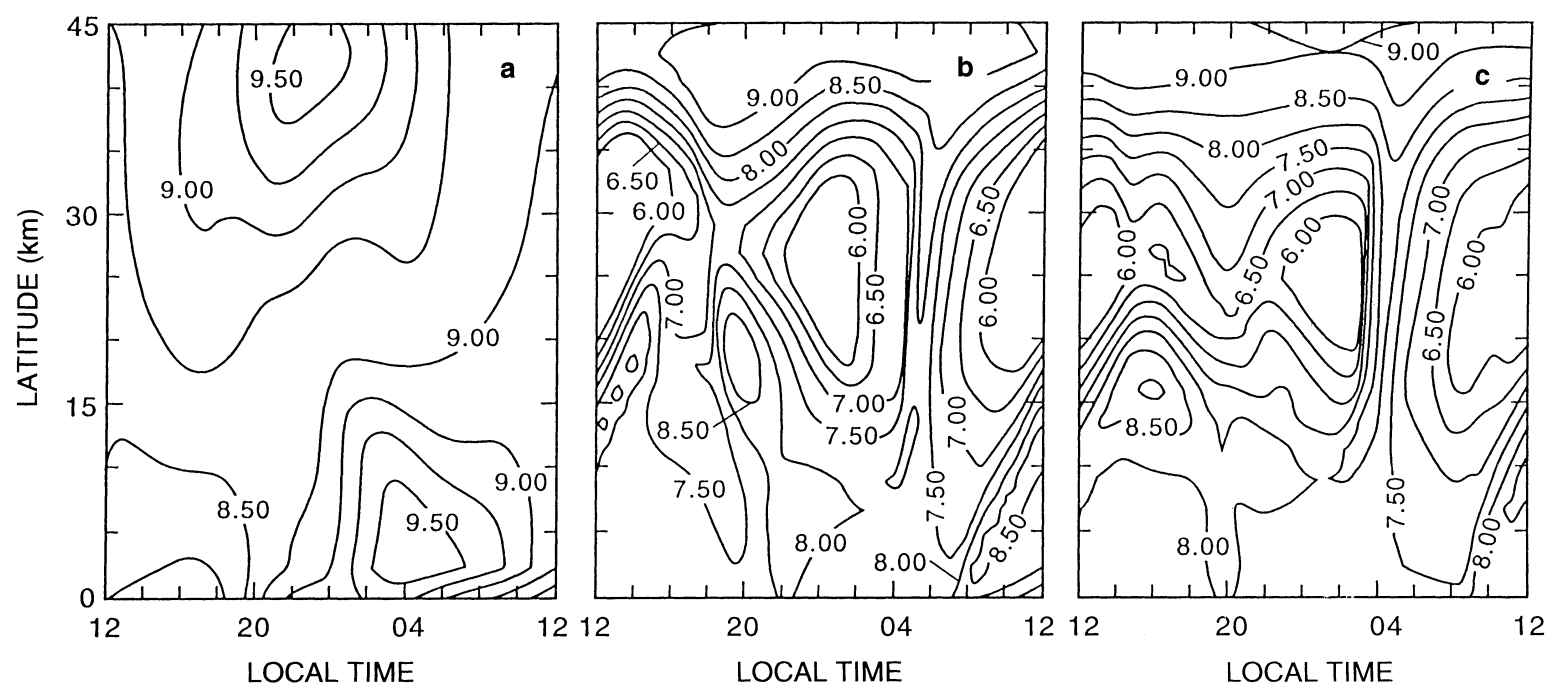

Fig. 12a-c. Same as Fig. 8, except due to transport by zonal and meridional winds and electric fields

winds and electric fields, complementing Fig. 8 (E-fields only) and Fig. 9 (winds only). Except for the tendency for higher densities to occur at higher latitudes (the result of electric field pumping), these distributions look quite different than those displayed in Figs. 8 and 9. The underlying difference is that electric fields have distributed the ions in significant populations to higher latitudes, where wind effects redistribute the ions in the vertical according to the latitude/local-time distribution of convergent and divergent nulls in the upper E-region and lower F-region. The minima and maxima in densities at the top of Fig. 11b can be found by placing an imaginary horizontal line across Fig. 12b; further, Fig. 12 gives some sense as to how the height/local-time distribution depicted in Fig. 11b will vary northward and southward of $22.5^{\circ}$ latitude.

Specific features in Fig. 12 can be traced back to the effects of either winds or electric fields. At the lowest altitude (Fig. 12a), having essentially no fine structure, shows the general appearance of a superposition of Figs. 8a and 9a: greatest densities are found at the high and low latitude and equatorial regions, following Fig. 8a at high latitude (due to the fountain effect) and Fig. 9a at low latitudes (due to the effectiveness of the p.m. zonal wind descending null). At $200 \mathrm{~km}$ the effect of combining the wind field and the electric field shows a striking result, as the upward $E \times B$ motion of the daytime field "pulls off" part of the a.m. descending layer, creating a low- to mid-latitude ridge to form in the 0800 to 1600 LT sector. The progression of this ridge to higher latitudes coincides with the variations of E-field transport in both latitude and local time (figures not shown). By 2000 LT the p.m. descending layer can be seen, maximizing at $20^{\circ}$ latitude, followed by the nighttime density valley and the a.m. layer. Global transport results in the high-latitude bulge which varies only little over the diurnal cycle, and the mid-latitude daytime valley, where neither winds nor the electric field (fountain effect) supply significant numbers of ions at this altitude. Finally, at $300 \mathrm{~km}$ a very similar picture emerges, but with decreased influence from the tidal wind field. Thus the main features that survive at this level are due to electric field forcing; a quick comparison to Fig. 9c shows how dramatic this can be at the higher altitudes.

\subsection{Magnetic storm simulation}

Simulating the effects of a magnetic storm on metallic ion dynamics is the first of two special-case scenarios investigated with the 2-D model. A magnetic storm would impact ion dynamics primarily by superimposing an electric field perturbation over the ambient field generated by the Richmond model, and secondarily through perturbations on composition and on thermospheric winds (winds were not altered in the numerical simulations). To obtain an assessment of the effects, a perturbing zonal field was imposed twice during the diurnal cycle, beginning at noon and again at midnight; thus an eastward (positive) field perturbation results in upward ion drifts. Each perturbation was three hours in duration: a one-hour linear ramp-up, one hour at maximum strength, and a one-hour linear ramp-down. The points in time at which each of these events occur are denoted by arrows on the plots to be presented, where 1 denotes the start time of the noon perturbation ramp-up, 2 the termination of ramp-up (maximum strength reached), 3 the commencement of ramp-down, and 4 the termination of the noon pulse. Arrows 5 through 8 identify, in numerical order, the same four events for the midnight pulse. Four strength values $\left(\mathrm{mVm}^{-1}\right)$ were evaluated: $+0.5,-0.5,+2.0,-2.0$. The effect on composition was reflected in the value of the magnetic activity index Ap, one of the calling arguments for the MSISE90 model; the index was increased from the quiet level of 10 to 80 for the $0.5 \mathrm{mVm}^{-1}$ cases and 200 for the $2.0 \mathrm{mVm}^{-1}$ cases. In order to separate the 
effects arising from the noon pulse and from the midnight pulse, an additional series of computer runs were made with the noon perturbations only, so that the effects of each pulse could be unabiguously identified.

In the interest of brevity, only the results for the $-20 \mathrm{mVm}^{-1}$ pulse at $9^{\circ}$ latitude are displayed here, in Fig. 13a. (The interested reader is referred to Carter (1995) for figures comparing various combinations of latitudes and substorm strengths.) Figure 13a may be compared with Fig. 10b, representing the simulation in the absence of electric field perturbations. Comparing the period between noon and $1500 \mathrm{UT}$, it is clear that the westward electric field perturbation has transported ions all the way down to the $125 \mathrm{~km}$ level over a very brief time span, increasing ion densities one or two orders of magnitude between 125 and $160 \mathrm{~km}$. Moreover, the descending layer formation just after 2000 LT is enhanced as a result of this additional source of ions which has been captured by the neutral wind field. As the midnight perturbation reaches maximum strength, it too drives ions downward to further feed and enhance the stagnation layer as it maximizes near $0600 \mathrm{LT}$ and $105 \mathrm{~km}$, increasing densities by a factor of 2 (log density from 10.25 to 10.50 ).

\subsection{Meteor shower simulation}

A second special-case scenario was undertaken to assess the effects of a severe but brief meteor shower on the spatial and temporal characteristics of metallic ions. Using data from McKinley (1961), the parameters chosen were a meteor entry rate of five times the ambient sporadic rate, a total duration of twelve hours, and a temporal pulse similar to that for the magnetic storm: a four-hour linear ramp-up, four hours at maximum intensity, and four hours linear ramp-down. For simplicity, the meteor size distribution and composition were assumed comparable to sporadics, so that the shower deposition rate was simply a superposition over the sporadic rate; thus, at maximum level, the total metallic deposition rate was six times the ambient rate. Two cases of this scenario were generated and evaluated: a shower centered at noon, and one at midnight. As for the magnetic storm scenario, the pertinent time points are identified on the plot by numbered arrows: 1 for start of ramp-up, 2 for completion of ramp-up, 3 for commencement of ramp-down, and 4 for termination.

Results for the noontime meteor shower scenario for $9^{\circ}$ latitude are displayed in Fig. 13b, which can be compared to the quiet-time reference results in Fig. 10b. Just after noon, log density levels are generally increased by 0.5 or roughly a threefold increase; by 3-4 hours after shower termination, the increase has dropped to 0.25 below $130 \mathrm{~km}$, and to 0.4 (factor of 2.5 ) above $130 \mathrm{~km}$; by $6-8$ hours after, the increase is now only about 0.10 to 0.15 . Lower altitudes would be expected to have a shorter recovery time since transport is either lateral or downward, with smaller electric field increase for upward transport. Levels aside, the morphology of the density pattern is virtually unaltered. Moving to $22.5^{\circ}$ latitude (not shown) the increase in $\log _{10}\left[\mathrm{Fe}^{+}\right]$is not as marked, by 0.25 at most during the shower and very small (about 0.10 or less) changes over the remainder of the diurnal cycle; by $160 \mathrm{~km}$ the differences are negligible. At $36^{\circ}$ the post-noon increase is similar to

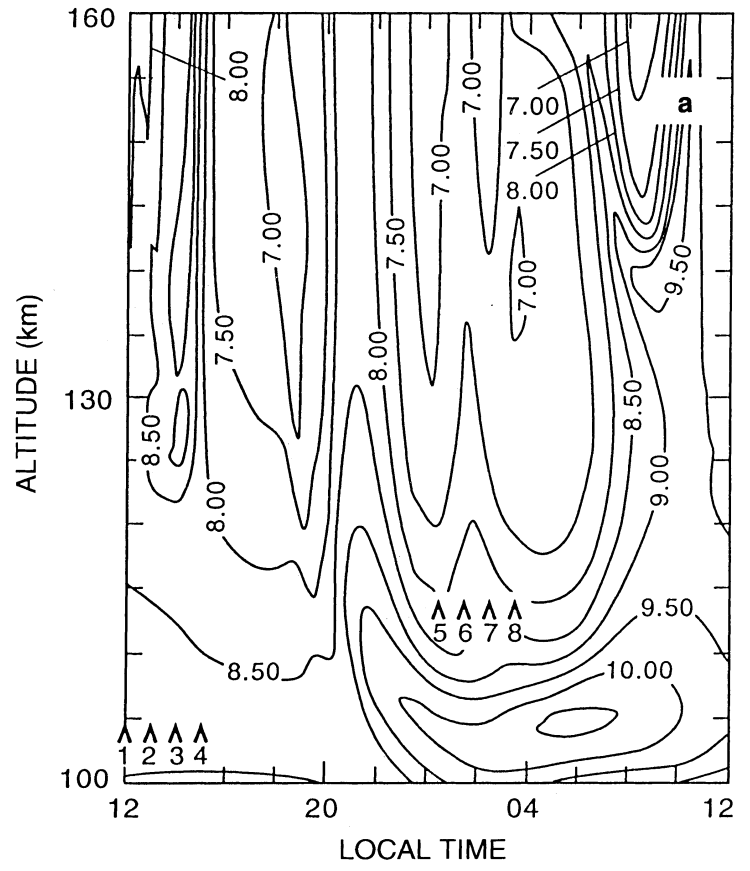

Fig. 13a, b. Height versus contours $\log _{10}\left[\mathrm{Fe}^{+}\right]$at $9^{\circ}$ latitude with meridional and zonal winds and electric field. a perturbed by $-2.0 \mathrm{mVm}^{-1}$ magnetic storm-induced pulse; $\mathbf{b}$ perturbed by noontime

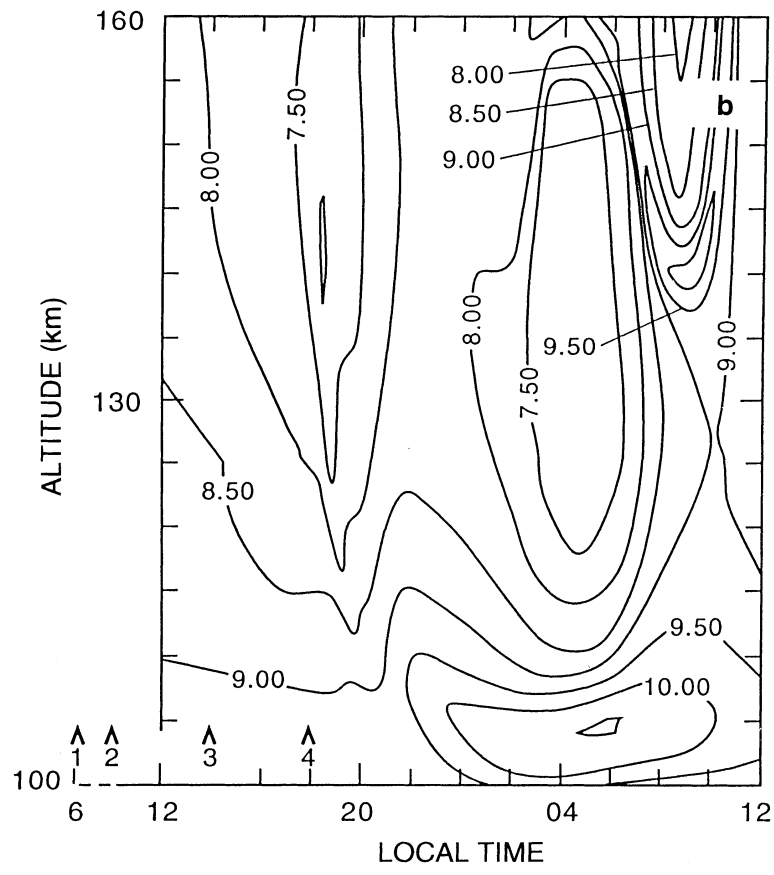

meteor shower. Compare with undisturbed contours in Fig. 10b. Labelled arrows are defined in the text 
that at $9^{\circ}$, at 0.5 , but the change in absolute magnitude is much smaller because of the lower contour values; for example at $9^{\circ}$ the increase is from 8.0 to 8.5 , or 100 to $316 \mathrm{~cm}^{-3}$, while at $36^{\circ}$ the increase is from 6.0 to 6.5 , or 1 to $3.16 \mathrm{~cm}^{-3}$. Thus the higher the latitude, the smaller the increase, due to the fact that the higher latitudes receive a larger fraction of their total metallic input via the fountain effect, which acts like a low-pass filter in smoothing out sudden changes in metallic deposition. The midnight scenario (not shown) shows a very sharp vertical density gradient forming at $2230 \mathrm{LT}$, the result of a rapid increase in deposition coincident with strong downward transport at this time. This gradient is so sharp that, over a 10-min interval, the ion density increases ten-fold at $127 \mathrm{~km}$ and by thirty-fold at $119 \mathrm{~km}$. Such drastic changes in local density over brief periods have indeed been observed on numerous occasions (i.e., see Hake et al., 1972; Mathews et al., 1993).

\subsection{Summary of model relevant to observations}

The foregoing series of simulations, incorporating both global meridional and vertical transport, has yielded a number of conclusive results that are relevant to existing observations, or those that may be achievable in the near future from the ground or space:

1. During a typical meteor shower, metallic ion densities undergo rapid, sizable increases, with the greatest change from ambient levels occurring at low altitudes. Such enhancements in lower ionosphere metallic densities associated with meteor showers have been observed numerous times (i.e., Narcisi, 1967; Kopp, 1997; Grebowsky et al., 1998, and references contained therein).

2. The balance of monatomic iron in the upper atmosphere is overwhelmingly (95\% to $99 \%$ ) in the ionized state, due to its relatively low ionization potential. This is consistent with earlier measurements of $\mathrm{Fe}$ and $\mathrm{Fe}^{+}$levels (Tepley et al., 1981).

3. Under typical local ambient conditions, ion transport is controlled more by neutral winds at low and mid latitudes, whereas the control shifts to electric fields at high latitudes (see Nygren et al., 1984; Bristow and Watkins, 1991; Kirkwood and Von Zahn, 1991).

4. For those altitudes where tidal winds exert an effect on ion transport, ion layering occurs on a semidiurnal basis over a wide latitude range, but layer structure shows considerable latitudinal dependence.

5. Reflecting the dynamics of the Richmond model, electric field induced motion is generally downward at night and upward at daytime, but the crossover points have considerable latitudinal dependence.

6. Model $\left[\mathrm{Fe}^{+}\right]$peaks, both in magnitude and altitude, are found to be in quite good agreement with observations (i.e., Kane et al., 1993), although much of the observational data base additionally includes ion peaks with lie below the lower limit of the 2-D model's spatial domain $(100 \mathrm{~km})$.

7. The phenomenon of "dumping", wherein layer peaks are found to lie consistently above the convergent null by 1 to $3 \mathrm{~km}$ (Alpers et al., 1993), is also observed in model output, i.e., compare late a.m. null locations in Fig. 11a to corresponding peaks in Fig. 11b

8. Metallic ion densities at altitudes significantly above the ablation profile do not correlate in time with the occurrence of meteor showers.

9. $\mathrm{F}$ region densities are highest at and near the dip equator, extending to higher altitudes during daytime hours, in general agreement with rocket and satellite measurements (Kumar and Hanson, 1980; Mende et al., 1985; Grebowsky and Reese, 1989).

\section{Summary and possible future directions}

\subsection{General comments on results}

The purpose of this work is seen as twofold: (1) to develop, design, and construct, from first principles, a comprehensive model of the full life cycle of metallics in the upper atmosphere, emphasizing the pivotal role played by ion transport mechanisms, in both the local and global sense, and (2) to exercise this model within a sufficiently large envelope of environmental parameters that an increased level of understanding can be gained of metallic ion dynamics. A corollary to better understanding is further development of the framework by which metallic ion observations can be incorporated into a complete and coherent theory encompassing both the chemistry and physics of atmospheric metallics.

Model results show that metallic ion behavior follows a coherent characteristic pattern. In the absence of winds and electric fields, the ion densities at low altitudes form a predictable steady-state pattern characterized by deposition in the 90 to $130 \mathrm{~km}$ region and eventual disappearance either by upward diffusion or downward settling into the chemical sink, with slight diurnal variation through the effects of photoionization and ambient ions on the neutral $\mathrm{Fe}$ reservoir. The inclusion of an electric field causes a substantial global re-distribution of ions through the meridional transport of the fountain effect, but at lower altitudes the absence of convergent nulls, at least at latitudes equatorward of $45^{\circ}$, prevents the formation of layers. Adding meridional and zonal winds contributing both divergent and convergent nulls bring in a new dimension of behavior: The vertical distribution now exhibits the formation and descent of thin, dense ion layers, with density changes of as much as a factor of $10^{4}$ over less than $20 \mathrm{~km}$ in altitude. The spatial and temporal properties of the layers produced through this simulation bear a close resemblance in several respects to that of $E_{s}$ events seen at several observatories, including recent results at Arecibo during the AIDA-89 campaign.

Expanding the model to include both vertical and meridional motion shows the dominating and pivotal influence of the fountain effect on global ion transport. The increased domain allowed for a number of functional dependencies to be revealed: the role played by the electric field in establishing and maintaining the fountain effect as the critical element in global transport; 
the latitudinal dependence of ion motion due to zonal and meridional winds, and to $\vec{E} \times \vec{B}$ drifts; the results of a change in the source function, whether in deposition rate or vertical profile, on the $\left[\mathrm{Fe}^{+}\right]$pattern; and the very "non-linear" way in which wind and E-field induced motions combine, in some cases creating a "traveling null", trapping metallic ions in an upper level transient layer which later dissipates away.

Overall, an improved understanding of certain aspects of the physics and chemistry underlying atmospheric metallic ion dynamics has been realized through the development and exercise of this model.

\subsection{Summary of results pertaining to localized layering}

An analysis of the results of the first series of simulations, with the 1-D version of the model, yields a number of results regarding localized transport. These are enumerated as follows:

1. In the absence of global transport, layer densities display a measurable sensitivity to the meteoric deposition altitude profile selected; a high altitude profile appears to agree best with measurements.

2. Descending layer structure and morphology is sensitive to the fine structure of the wind field; the evening descending layer associated with the zonal wind component is very diffuse and extended compared to that associated with the meridional wind, and both evening layers display considerably less intensity than the morning descending layers.

3 . The simulation reproduces the "dumping" effect in the morning layers, wherein ions are left behind at upper levels when the wind field null descent rate exceeds the ion's mobility at lower altitudes, due to the very rapid increase in collision rate with decreasing altitude.

4. Chemical reactions may play a critical role in converting metallic ions to neutrals and back, but these effects become significant only at low $(<100 \mathrm{~km})$ altitudes, due to the importance of three-body reactions. 5. A layer structure formed from combined zonal and meridional winds is not simply a superposition of two different layer structures, but shows a strong altitudeweighting effect, in that the zonal wind predominates at low altitudes and the meridional wind at high altitudes, in conformity with the generalized equation of motion (EOM).

6. Assuming wind and E-field models are typical, it can be concluded that at middle and low latitudes winds have a greater effect on metallic ions, due in part to the fact that E-field transport is altitude-weighted relative to wind-driven transport, as can be seen from the generalized EOM. Thus layering, which occurs mostly at the lower altitudes, is affected much more by winds.

\subsection{Summary of results pertaining to global transport}

The 2-D simulations have broadened and expanded the understanding of metallic ion dynamics, especially with regard to latitudinal differences and the global influence of the fountain effect. The important results are summarized as follows:

1. The daytime global electric field plays a vital role through the upward transport of metallic ions in the equatorial region, to a sufficient high altitude where gravity-induced downward drift along geomagnetic field lines caries them into mid and high latitude regions. One effect of this transport is that the highest metallic ion densities in the upper $\mathrm{F}$ region are found at the equatorial latitudes.

2. The fountain effect described results in a significant ion density enhancement at mid-latitudes (above $30^{\circ}$ magnetic); however, the combined influence of meteoric deposition and $\mathrm{E}$ region charge exchange causes equatorial densities to be enhanced almost as much throughout the lower (E region) altitudes.

3 . In spanning the low- to mid-altitude range from 100 to $300 \mathrm{~km}$, the lowest levels show an ion density primarily dependent on local time, whereas the higher levels show a density dependence more on latitude and less on local time.

4. Because of the separate ways in which zonal winds and meridional winds affect ion motion, the zonal component is more effective at lower latitudes and lower altitudes, and conversely the meridional component becomes increasingly effective at higher altitudes and high latitudes (horizontal transport becomes a factor at higher latitudes).

5. Because both electric field-induced and tidal windinduced velocities depend on latitude in different ways, and the two must be vectorially combined to form the ion velocity field, a descending convergent null can be rapidly transformed in shape or even destroyed as an observer varies latitude.

6. With global transport from the fountain effect included, the local transport and layering characteristics of metallic ions become less sensitive to the altitude profile of meteor ablation. In the case of a very low profile, layering will still occur but will be most prominent at levels below $100 \mathrm{~km}$.

7. A magnetic storm perturbation has more of an immediate effect on metallic ion dynamics at low latitudes than high latitudes (excepting of course auroral zone latitudes). A severe storm can drastically transform the typical ion distribution pattern, the outcome being dependent on the relative strengths and phases of the electric field and tidal winds.

8. The intensity of tidal ion layering is generally sensitive to the occurrence of a meteor shower, with the sensitivity further enhanced at low latitudes. If a shower occurs during the optimum phase of a descending convergent null, the local ion density increase can be extremely high.

9. A change in the relative ratio of $\mathrm{Fe}$ and $\mathrm{Fe}^{+}$in the meteoric source function has a rather surprising effect on the global metallic ion distribution; an increase in the $\mathrm{Fe} / \mathrm{Fe}^{+}$ratio results in an intensification of ion layering at low latitudes, and lighter layering at mid and high latitudes, due to the fountain effect on global transport. 
10. The conversion of $\mathrm{Fe}$ to $\mathrm{Fe}^{+}$occurs predominantly through charge exchange with ambients, with only about $1 \%$ through photoionization. Furthermore, the fraction of conversion for each ambient species is highly latitude-dependent: $\mathrm{NO}^{+} \mathrm{O}_{2}^{+}$are roughly equal and far outweigh $\mathrm{O}^{+}$at equatorial and low latitudes, but by $40^{\circ}$ latitude the rates for all three are comparable.

\subsection{Possible directions for future work}

These findings have formed a foundation on which further advances can be built through future development and expansion of model. A promising direction for future research is more detailed parameterization through incorporation of observational data, facilitating a closer link between the functional elements of the model and the existing data base. Although the model in its current form is almost entirely based on first principle-level physics and chemistry, continued evolution will necessitate a progressively more empirical approach if the model is to reflect observational findings to any significant extent.

Having made these initial advances in building on the theoretical foundation, a high potential exists for future contributions. The inclusion of gravity wave field superimposed on the current tidal wind field may allow for the simulation of layer breakup and bifurcation, as has been observed on several occasions (Kane et al., 1993; Mathews et al., 1993). The model has potential application in advancing the theory and understanding of nighttime $\mathrm{E}$ region conductivity and consequent $\mathrm{E} / \mathrm{F}$ region coupling mechanisms through ion layer formation. Incorporating the appropriate geometric variations due to longitude may reveal a new dimension of geographic dependence similar to an earlier $\mathrm{Mg}^{+}$global transport model (Fesen et al., 1983). The chemical aspects of this science point to potential new areas of theoretical contributions through modeling, in spite of the sparse chemical reaction rate data base. The acquisition of accurate chemical rate data would facilitate a major advance in modeling the very low altitude region (below $100 \mathrm{~km}$ ), considered by many workers the key to fully understanding those processes leading to sudden neutral layers, especially sodium. However, incorporating complex ion chemistry and colloidal processes may prove to be enormous obstacles on realizing this level of model enhancement. One final area of model improvement worthy of mention is in layer formation, to the extent that a virtually perfect match to observation should be possible, through such avenues as fine-tuning the tidal wind field and increasing the spatial resolution.

It would appear that the most realistic methodology for realizing small but cumulative model improvements is to ensure that the fruits of observational and experimental efforts are incorporated as they become available to shape the model into a more accurate representation of the physical system of interest. Moreover, the expected availability of new sources of data from ongoing experiments and observational programs can be utilized to enhance and improve upon predictive capabilities which of course any numerical model must have in order to be of lasting value to the scientific community.

Acknowledgements. This work was supported under Grants F49620-92-J-0092 and F49620-95-1-0118 from the US Air force Office of Sponsored Research to the University of Colorado.

Topical Editor F. Vial thanks C. A. Tepley and another referee for their help in evaluating this paper.

\section{References}

Aiken, A. C., and R. A. Golberg, Metallic ions in the equatorial ionosphere, J. Geophys. Res., 78, 734, 1973.

Aiken, A. C., R. A. Golberg, and A. Azcarrage, Ion composition during the formation of mid-latitude $\mathrm{E}_{\mathrm{S}}$ layer, Space Res. XIV, 283, 1974.

Aiken, A. C., R. A. Goldberg, W. Jones and J. A. Kane, Observations of the mid-latitude lower ionosphere in winter, J. Geophys. Res., 82, 1869, 1977.

Alpers, M., T. Blix, S. Kirkwood, D. Krankowsky, F. J. Lubken, S. Lutz, and U. von Zahn, First simultaneous measurements of neutral and ionized iron densities in the upper mesosphere. J. Geophys. Res., 98, 275, 1993.

Banks, P. M., and G. Kockarts, Aeronomy, Part A, Academic Press, 430 pp., New York, NY, 1973.

Bates, D. R., and A. Dalgarno, Atomic and molecular processes Ed. D.R. Bates, Academic Press, New York, NY, 1962.

Bilitza, D., International reference ionosphere 1990, NSSDC/ WDCA-R\&S 90-22, National Space Science Data Center, World Data Center A for Rockets and Satellites, Greenbelt, MD, U.S.A., 1990.

Bristow, W. A., and B. J. Watkins, Numerical solution of the formation of thin ionization layers at high latitudes, Geophys. Res. Lett., 18, 404, 1991.

Brown, T. L., The chemistry of metallic elements in the ionosphere and mesosphere, Chem. Rev., 73, 645, 1973.

Carter, L. N., A comprehensive model of global transport and localized layering of metallic ions in the upper atmosphere, $\mathrm{PhD}$ Thesis, Graduate School, Boston University, Boston, MA, U.S.A., 1995.

Chimonas, G., and W. I. Axford, Vertical movement of temperature zone sporadic E layers, J. Geophys. Res., 73, 111, 1968.

Crary, D. J., and J. M. Forbes, The dynamic ionosphere over Arecibo: a theoretical investigation, J. Geophys. Res., 91, 249, 1986.

Dungey, J. W., The influence of the geomagnetic field on turbulence in the ionosphere, J. Atoms. Terr. Phys., 8, 39, 1956.

Dungey, J. W., Effect of a magnetic field on turbulence in an ionized gas, J. Geophys. Res., 64, 2188, 1959.

Elford, W. G., and G. S. Hawkins, Meteor echo rates and the flux of sporadic meteors. Harvard Radio Meteor, Project Res. Rep. 9, 24 pp., Cambridge, MA, 1964.

Ferguson, E. E., and F. C. Fehsenfeld, Some aspects of the metal ion chemistry of the earth's atmosphere, J. Geophys. Res., 73, 6215, 1968.

Fesen, C. G., The $\mathrm{Mg}^{+}$airglow in the low latitude ionosphere: observations and theoretical modeling, $\mathrm{PhD}$ thesis, 228 pp., The University of Michigan, Ann Arbor, July 1981.

Fesen, C. G., P. B. Hays, and D. N. Anderson Theoretical modeling of low latitude $\mathrm{Mg}^{+}$, J. Geophys. Res., 88, 3211, 1983.

Forbes, J. M., Atmospheric tides 1. Model description and results for the solar diurnal component, J. Geophys. Res., 87, 5222, 1982a.

Forbes, J. M., Atmospheric tides 2. The solar and lunar semidiurnal component, J. Geophys. Res., 87, 5241, 1982 b.

Gadsden, M., Metallic atoms and ions in the upper atmosphere, Ann. Geophysicae 26, 141, 1970. 
Gallagher, D. L., P. D. Craven, and R. H. Comfort, An empirical model of the earth's plasmaphere, Adv. Space Res. VIII, 15, 1988.

Gardner, C. S., T. J. Kane, D. C. Senft, J. Qian, and G. C. Papen, Simultaneous observation of sporadic E, Na, Fe, and $\mathrm{Ca}^{+}$ layers at Urbana, Illinois: three case studies, J. Geophys. Res., 98, 16, 865, 1993.

Gardner, J., R. A. Viereck, E. Murad, S. T. Lai, D. Knecht, C. P. Pike, L. Broadfoot, E. Anderson, W. Sandel, and W. J. McNeil, $\mathrm{Mg}^{+}$and other metallic emissions observed in the thermosphere, Proc. SPIE Int. Soc. Opt. Eng., 2266, 262, 1994.

Gardner, J., R. A. Viereck, E. Murad, D. Knecht, C. P. Pike, L. Broadfoot, and E. Anderson, Simultaneous observations of neutral and ionic magnesium in the thermosphere, Geophys. Res. Lett., 22, 2119, 1995.

Gerard, J. C., Satellite measurements of high-altitude twilight $\mathrm{Mg}^{+}$ emission, J. Geophys. Res., 81, 83, 1976.

Gerard, J. C., and A. Monfils, The Mg II equatorial airglowaltitude distribution, J. Geophys. Res., 83, 4389, 1978.

Goldberg, R. A., and G. Witt, Ion composition in a noctilucent cloud region, J. Geophys. Res., 82, 2619, 1977.

Grebowsky, J. M., and H. C. Brinton, $\mathrm{Fe}^{+}$ions in the high-latitude F-region, Geophys. Res. Lett., 5, 791, 1978.

Grebowsky, J. M., and N. Reese, Another look at equatorial metallic ions in the F-region, J. Geophys. Res., 94, 5427, 1989.

Grebowsky, J. M., R. A. Goldberg, and W. D. Pesnell, Do meteor showers significantly perturb the ionosphere? J. Atoms. SolarTerr. Phys., 60, in press, 1998.

Hake, R. D., Jr., D. E. Arnold, D. W. Jackson, W. E. Evans, B. P. Ficklin, and R. A. Long, Dye-laser observations of the nighttime atomic sodium layer, J. Geophys. Res., 77, 6839, 1972.

Hanson, W. B., and S. Sanitani, Meteoric ionsabove the $\mathrm{F}_{2}$ peak, $J$. Geophys. Res., 75, 5503, 1970.

Hanson, W. B., D. L. Sterling, and R. F. Woodman, Source and identification of heavy ions in the equatorial F-layer, $J$. Geophys. Res., 77, 5530, 1972.

Harper, R. M., Some results on mean tidal structure and day-today variability over Arecibo, J. Atmos. Terr. Phys., 43, 255, 1981.

Hedin, A. E., Extension of the MSIS thermosphere model into the middle and lower atmosphere, J. Geophys., Res., 96, 1159, 1991.

Istomin, V. G., Absolute concentrations of ion components of the earth's atmosphere, Planet. Space Sci., 11, 169, 1963.

Kane, T. J., and C. S. Gardner, Structure and seasonal variability of the nighttime mesospheric $\mathrm{Fe}$ layer at midlatitudes, $J$. Geophys. Res., 98, 16 875, 1993.

Kane, T. J., C. A. Hostetler, and C. S. Gardner, Horizontal and vertical structure of the major sporadic sodium layer events observed during ALOHA-90, Geophys. Res. Lett., 18, 1365, 1991.

Kane, T. J., C. S. Gardner, Q. Zhou, J. D. Mathews, and C. A. Tepley, Lidar, radar, and airglow observations of a prominent sporadic $\mathrm{Na}$ /sporadic E layer event at Arecibo during AIDA89, J. Atmos. Terr. Phys., 55, 499, 1993.

Kirkwood, S., and U. Von Zahn, On the role of auroral electric fields in the formation of low altitude sporadic-E and sudden sodium layers, J. Atoms. Terr. Phys., 53, 389, 1991.

Kopp, E., On the abundance of metal ions in the lower ionosphere, J. Geophys. Res., 102, 9667, 1997.

Kumar, S., and W. B. Hanson, The morphology of metallic ions in the upper atmosphere, J. Geophys. Res., 85, 6783, 1980.

MacLeod, M. A., Sporadic E theory. I. Collision-geomagnetic equilibrium, J. Atmos. Sci., 23, 96, 1966.

MacLeod, M. A., T. J. Keneshea, and R. S. Narcisi, Numerical modeling of a metallic ion sporadic-E layer, Radio Sci., 10, 371, 1975.

Mathews, J. D., and F. S. Bekeny, Upper atmospheric tides and the vertical motion of ionospheric sporadic at Arecibo, J. Geophys. Res., 84, 2743, 1979.
Mathews, J. D., and Y. T. Morton, and Q. Zhou, Observations of ion layer motions during the AIDA campaign, J. Atoms. Terr. Phys., 55, 447, 1993.

McKinley, D. W. R., Meteor science and engineering, 301 pp., McGraw-Hill, New York, 1961.

McNeil, W. J., S. T. Lai, and E. Murad, A model for meteoric magnesium in the ionosphere, J. Geophys. Res., 101, 5251, 1996.

Mende, S. B., G. R. Swenson, and K. L. Miller, Observations of E and $\mathrm{F}$ region $\mathrm{Mg}^{+}$from Spacelab 1, J. Geophys. Res., 90, 6667, 1985.

Mendillo, M., J. Semeter, and J. Noto, Finite element simulation (FES): a computer modeling technique for studies of chemical modification of the ionosphere, Adv. Space Res., 13(10), 55, 1993.

Morton, Y. T., and J. D. Mathews, Effects on the 13-14 March 1989 geomagnetic storm on the E region tidal ion layer structure at Arecibo during AIDA, J. Atmos. Terr. Phys., 55, 467, 1993.

Morton, Y. T., J. D. Mathews, and Q. Zhou, Further evidence for a 6-h tide above Arecibo, J. Atmos. Terr. Phys., 55, 459, 1993.

Narcisi, R. S., Processes associated with metal-ion layers in the E region of the ionosphere, Space Res. VIII, 360, 1967.

Narcisi, R. S., and A. D. Bailey, Mass spectrometric measurements of positive ions at altitudes form 64 to 112 kilometers, $J$. Geophys. Res., 70, 3687, 1965.

Nygren, T., L. Jalonen, J. Oskman, and T. Turunei, The role of electric field and neutral wind direction in the formation of sporadic E-layers, J. Atmos. Terr. Phys., 46, 373, 1984.

Osterman, G. B., R. A. Heelis, and G. J. Bailey, Modeling the formation of intermediate layers at Arecibo latitudes, $J$. Geophys. Res., 99, 11357, 1994.

Plane, J. M. C., The chemistry of meteoric metals in the earth's upper atmosphere, Int. Rev. Phys. Chem., 10, 55, 1991.

Plane, J. M. C., and M. Helmer, Laboratory studies of the chemistry of meteoric metals, Res. Chem. Kinet., 2, 213, 1994.

Plane, J. M. C., and M. Helmer, Laboratory study of the reactions $\mathrm{Mg}+\mathrm{O}_{3}$ and $\mathrm{MGO}+\mathrm{O}_{3}$, implications for the chemistry of magnesium in the upper atmosphere, Faraday Discuss. Chem. Soc., 100, 1, 1995.

Plane J. M. C., and D. Husain, Determination of the absolute rate constant for the reaction $\mathrm{O}+\mathrm{NaO}=\mathrm{Na}+\mathrm{O}_{2}$ by timeresolved atomic chemiluminescence at $589 \mathrm{~nm}, J$. Chem. Soc. Faraday Trans., 82, 2047, 1986.

Richmond, A. D., M. Blanc, B. A. Emery, R. H. Wand, B. G. Fejer, R. F. Woodman, S. Ganguly, P. Amayenc, R. A. Behnke, C. Calderon, and J. V. Evans, An empirical model of quiet-day ionospheric electric fields at middle and low latitudes, $J$. Geophys. Res., 85, 4658, 1980.

Richter, E. S., and C. F. Sechrist Jr., A meteor ablation-cluster ion atmospheric sodium theory, Geophys. Res. Lett., 6, 183, 1979a.

Richter, E. S., and C. F. Sechrist Jr., A cluster ion chemistry for the mesosphere sodium layer, J. Atoms. Terr. Phys., 41, 579, 1979b.

Roble, R. G., E. C. Ridley, A. D. Richmond, and R. E. Dickinson, A coupled thermosphere/ionosphere general circulation model, Geophys. Res. Lett., 15, 1325, 1988.

Rutherford, J. A., and D. A. Vroom, Formation of iron ions by charge transfer, J. Chem. Phys., 57, 3091, 1972.

Swider, W., Processes for meteoric elements in the E-region, Planet. Space Sci., 17, 1233, 1969.

Taylor, H. A., Jr., Parametric description of thermospheric ion composition results, J. Geophys. Res., 78, 315, 1973.

Tepley, C. A., J. W. Meriwether, Jr., and J. C. G. Walker, Observations of neutral ion emission in twilight spectra, $J$. Geophys. Res., 86, 4831, 1981.

Tong, Y. U., J. D. Mathews, and W. P. Ying, An upper E-region quarterdiurnal tide at Arecibo?, J. Geophys. Res., 93, 10047, 1988.

US Standard Atmosphere, 1976, NOAA-S/T 76-1562, US Government Printing Office, Washington, D.C., 1976.

Whitehead, J. D., The formation of the sporadic-E Layer in the temperate zones, J. Atmos. Terr. Phys., 20, 49, 1961. 
Whitehead, J. D., Survey of sporadic E processes, Space Res. VII, 89, 1966.

Wilkinson, P. J., E. P. Szuszczewicz, and R. G. Roble, Measurements and modelling of intermediate, dzescending and sporadic layers in the lower ionosphere: results and implications for global-scale ionospheric-thermospheric studies, Geophys. Res. Lett., 19, 95, 1992.
Young, J. M., C. Y. Johnson, and J. C. Holmes, Positive ion composition of a temperate-latitude sporadic E layer as observed during a rocket flight, J. Geophys. Res., 72, 1473, 1967.

Zbinden, P. A., M. A. Hidalgo, P. Eberhardt, and J. Geiss, Mass spectrometer measurements of the positive ion composition in the D and E regions of the ionosphere, Planet. Space Sci., 23, $1621,1975$. 